\title{
Discovery of different metabotypes in overconditioned dairy cows by means of machine learning
}

\author{
Morteza H. Ghaffari, ${ }^{1}$ Amirhossein Jahanbekam, ${ }^{2}$ Christian Post, ${ }^{1}$ Hassan Sadri, ${ }^{3 *}$ Katharina Schuh, ${ }^{1,4}$ \\ Christian Koch, ${ }^{5}$ and Helga Sauerwein ${ }^{1} \dagger$ \\ ${ }_{1}^{1}$ Institute of Animal Science, Physiology Unit, University of Bonn, 53115 Bonn, Germany \\ ${ }^{2}$ Department of Epileptology, University of Bonn, Bonn 53127, Germany \\ ${ }^{3}$ Department of Clinical Science, Faculty of Veterinary Medicine, University of Tabriz, 516616471 Tabriz, Iran \\ ${ }^{4}$ Department of Life Sciences and Engineering, Animal Nutrition and Hygiene Unit, University of Applied Sciences Bingen, \\ 55411 Bingen am Rhein, Germany \\ ${ }^{5}$ Educational and Research Centre for Animal Husbandry, Hofgut Neumühle, 67728 Münchweiler an der Alsenz, Germany
}

\begin{abstract}
Using data from targeted metabolomics in serum in combination with machine learning (ML) approaches, we aimed at (1) identifying divergent metabotypes in overconditioned cows and at (2) exploring how metabotypes are associated with lactation performance, blood metabolites, and hormones. In a previously established animal model, 38 pregnant multiparous Holstein cows were assigned to 2 groups that were fed differently to reach either high (HBCS) or normal (NBCS) body condition score (BCS) and backfat thickness (BFT) until dryoff at $-49 \mathrm{~d}$ before calving [NBCS: BCS $<3.5(3.02$ $\pm 0.24)$ and $\mathrm{BFT}<1.2 \mathrm{~cm}(0.92 \pm 0.21)$, mean $\pm \mathrm{SD}$; HBCS: $\mathrm{BCS}>3.75(3.82 \pm 0.33)$ and BFT $>1.4 \mathrm{~cm}$ $(2.36 \pm 0.35)]$. Cows were then fed the same diets during the dry period and the subsequent lactation, and maintained the differences in BFT and BCS throughout the study. Blood samples were collected weekly from 7 wk antepartum (ap) to 12 wk postpartum (pp) to assess serum concentrations of metabolites (by targeted metabolomics and by classical analyses) and metabolic hormones. Metabolic clustering by applying 4 supervised ML-based classifiers [sequential minimal optimization (SMO), random forest (RF), alternating decision tree (ADTree), and naïve Bayes-updatable (NB)] on the changes (d 21 pp minus d 49 ap) in concentrations of 170 serum metabolites resulted in 4 distinct metabolic clusters: HBCS predicted HBCS (HBCS-PH, $\mathrm{n}=13$ ), HBCS predicted NBCS (HBCS-PN, $\mathrm{n}=6$ ), NBCS predicted NBCS (NBCS-PN, $\mathrm{n}=15$ ), and NBCS predicted HBCS (NBCS-PH, $\mathrm{n}=4$ ). The accuracies of SMO, RF,
\end{abstract}

Received April 6, 2020.

Accepted May 22, 2020.

${ }^{*}$ H. Sadri was a visiting scientist at the Institute of Animal Science, Physiology Unit, University of Bonn, 53115 Bonn, Germany, at the time the research was done.

†Corresponding author: sauerwein@uni-bonn.de
ADTree, and NB classifiers were $>70 \%$. Because the number of NBCS-PH cows was low, we did not consider this group for further comparisons. Dry matter intake $(\mathrm{kg} / \mathrm{d}$ and percentage of body weight) and energy intake were greater in HBCS-PN than in HBCS-PH in early lactation, and HBCS-PN also reached a positive energy balance earlier than did HBCS-PH. Milk yield was not different between groups, but milk protein percentage was greater in HBCS-PN than in HBCS-PH cows. The circulating concentrations of fatty acids (FA) increased during early lactation in both groups, but HBCS-PN cows had lower concentrations of $\beta$-hydroxybutyrate, indicating lower ketogenesis compared with HBCS-PH cows. The concentrations of insulin, insulin-like growth factor 1, leptin, adiponectin, haptoglobin, glucose, and revised quantitative insulin sensitivity check index did not differ between the groups, whereas serum concentrations of glycerophospholipids were lower before calving in HBCS-PH than in HBCS-PN cows. Glycine was the only amino acid that had higher concentration after calving in HBCS-PH than in HBCS-PN cows. The circulating concentrations of some short- $(\mathrm{C} 2, \mathrm{C} 3$, and C4) and long-chain (C12, C16:0, C18:0, and C18:1) acylcarnitines on d $21 \mathrm{pp}$ were greater in HBCS-PH than in HBCS-PN cows, indicating incomplete FA oxidation. In conclusion, the use of ML approaches involving data from targeted metabolomics in serum is a promising method for differentiating divergent metabotypes from apparently similar BCS phenotypes. Further investigations, using larger numbers of cows and farms, are warranted for confirmation of this finding.

Key words: body condition, metabolomics, machine learning, periparturient cow

\section{INTRODUCTION}

High-yielding dairy cows might fail in adapting to metabolic and physiological changes when entering lac- 
tation due to physiological imbalances and metabolic dysregulation (Sundrum, 2015; Wankhade et al., 2017), which in turn will lead to higher incidence of metabolic diseases (LeBlanc et al., 2006). Overconditioning around calving is usually associated with metabolic abnormalities and increased risk for metabolic disorders in early lactation (Berry et al., 2006; Roche et al., 2009; Roche et al., 2013). As recently reviewed (Blüher, 2020), evidence from clinical observations, epidemiological, prospective cohort, and intervention studies in humans indicates that obesity is not necessarily related to an unhealthy phenotype. Considering the concept of "metabolically healthy obesity" (MHO) from human medicine (Stefan et al., 2013; Bala et al., 2016) for overconditioned dairy cows could be interesting for scrutinizing the informative value of body condition in terms of metabolic health. Admittedly the metabolic situation of obese humans and overconditioned dairy cows is utterly different: in contrast with obese humans, dairy cows undergo rapid and comprehensive metabolic changes during the transition from late pregnancy into lactation.

Metabolites represent the end products of cellular processes; large-scale metabolic profiling can be used to discriminate between diseased and healthy individuals with remarkably high accuracy (Schicho et al., 2012; Cirulli et al., 2019). Metabolomics has also been successfully applied for differentiating metabolite patterns from $\mathrm{MHO}$ and metabolically unhealthy obese humans (Bagheri et al., 2018). Classically, elevated circulating concentrations of BHB and fatty acids (FA), as well as reduced blood levels of glucose, are considered indicative of an imbalanced metabolic status and thus greater risk for an unsuccessful transition from pregnancy to lactation (Ingvartsen et al., 2003; Puppel and Kuczynska, 2016). Extending the analytical spectrum to metabolomics, Rico et al. (2015) pointed out that increasing concentrations of ceramides in circulation indicate insulin resistance and are likely involved in the homeorhetic adaptation to early lactation. Moreover, branched-chain AA degradation antepartum (ap) and mitochondrial $\beta$-oxidation of long-chain FA, along with FA metabolism, purine metabolism, and alanine metabolism postpartum (pp) were identified as enriched pathways in overconditioned cows compared with cows at normal body condition (Ghaffari et al., 2019).

However, the variation of metabolomic profiles within a cohort of overconditioned cows during the transition period has not been addressed previously. Given the concept of MHO, we hypothesized that subgroups of metabolically balanced and unbalanced individuals may exist among dairy cows that were classified as overconditioned by BCS and backfat thickness (BFT) at calving. To test this hypothesis, we used machine learning (ML) approaches on data obtained by targeted metabolomics from serum samples collected from cows throughout the transition period. Machine learning is widely used in system biology (Swan et al., 2015; Kaakinen et al., 2018; Perakakis et al., 2018) including metabolomics (Costello and Martin, 2018; Beirnaert et al., 2019; Ghaffari et al., 2019). The objectives of the present study thus were (1) to evaluate whether metabolically balanced overconditioned (MBO) cows exist in a cohort of overconditioned periparturient cows, and (2) to compare performance, as well as longitudinal metabolic and endocrine changes between these MBO cows and the remaining metabolically imbalanced subgroup.

\section{MATERIALS AND METHODS}

\section{Basic Trial: Comparison of High Versus Normal Body Condition}

The basic setup of the experimental model for studying dairy cows with high or normal BCS (HBCS or NBCS) around calving together with the results from classical metabolites, metabolic hormones, and performance, including BCS, BFT, and energy balance (EB), have been described previously in detail by Schuh et al. (2019). In brief, 38 multiparous German Holstein cows (parity: $2.5 \pm 0.5$, mean $\pm \mathrm{SD}$ ) were allocated 15 wk before their anticipated calving date to either the NBCS ( $\mathrm{n}=19$; parity: $2.42 \pm 1.84$; BW: $665 \pm 64 \mathrm{~kg}$, mean $\pm \mathrm{SD})$ or the HBCS group $(\mathrm{n}=19$; parity: 3.37 $\pm 1.67 ; \mathrm{BW}: 720 \pm 57 \mathrm{~kg}$ ). The 2 groups were initially selected from the entire herd (150 cows) using their history of BCS and BFT records from the year preceding the trial to find cows divergent in both variables, to create 2 groups with equal numbers. The preselected cows were also stratified for comparable milk yields (NBCS: 10,361 kg $\pm 302 \mathrm{~kg}$; HBCS: 10,315 $\pm 437 \mathrm{~kg}$, mean \pm SD). From wk 15 ap (Figure 1), NBCS cows (BCS = $3.05 \pm 0.20, \mathrm{BFT}=0.87 \pm 0.28$, mean $\pm \mathrm{SD}$ ) were fed a low-energy ration, as recommended for late lactation $\left(\mathrm{NE}_{\mathrm{L}} 6.8 \mathrm{MJ} / \mathrm{kg}\right.$ of $\left.\mathrm{DM}\right)$, and HBCS cows $(\mathrm{BCS}=3.45$ $\pm 0.24, \mathrm{BFT}=1.36 \pm 0.39 \mathrm{~cm}$ ) were fed a high-energy ration $(7.2 \mathrm{MJ} / \mathrm{kg}$ of $\mathrm{DM})$ to reach divergent $\mathrm{BCS}$ and BFT at drying-off (wk 7 ap; NBCS: BCS $=3.47 \pm$ $0.42, \mathrm{BFT}=0.1 .30 \pm 0.32 ; \mathrm{HBCS}: \mathrm{BCS}=3.83 \pm 0.41$, $\mathrm{BFT}=2.03 \pm 0.48 \mathrm{~cm})$.

\section{Sampling}

Body condition score was estimated on a 5-point scale $(1=$ emaciated; $5=$ extremely fat $)$ with 0.25 incre- 


\section{Basic trial}

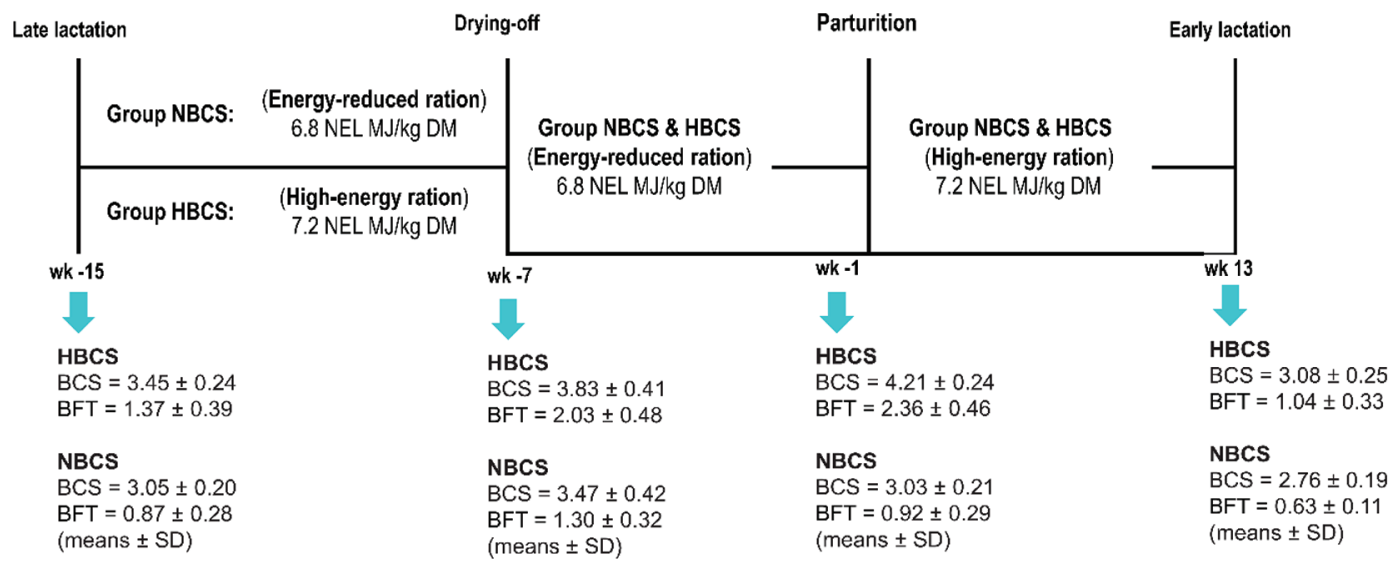

Figure 1. Design of the basic experiment. Cows with normal BCS (NBCS, $n=19)$ and cows with high BCS $(\mathrm{HBCS}, \mathrm{n}=19)$. BFT $=$ backfat thickness.

ments (Edmonson et al., 1989) every $2 \mathrm{wk}$ (15 wk ap to $12 \mathrm{wk}$ pp), and BFT was assessed in the sacral region at the same times using ultrasonography as described previously (Schuh et al., 2019). Targeted metabolomic analyses were performed in serum samples obtained before the morning feeding on $\mathrm{d}-49$ ap and $\mathrm{d} 21 \mathrm{pp}$ using the AbsoluteIDQ p180 Kit (Biocrates Life Sciences AG, Innsbruck, Austria), as previously described, to compare the HBCS with the NBCS group (Ghaffari et al., 2019). Blood samples were collected weekly (from wk 7 ap until wk $12 \mathrm{pp}$ ) from the tail vein to analyze FA, BHB, leptin, adiponectin, insulin, glucose, and haptoglobin, and to calculate the revised quantitative insulin sensitivity check index (RQUICKI), as previously described by Schuh et al. (2019). Individual feed intake was recorded daily, and BW was recorded weekly. Cows were milked twice daily at 0500 and 1530 $\mathrm{h}$ in a milking parlor (GEA Farm Technologies GmbH, Boenen, Germany). Net energy requirement for pregnancy, $\mathrm{NE}_{\mathrm{M}}, \mathrm{NE}_{\mathrm{L}}, \mathrm{ECM}$, and $\mathrm{EB}$ were calculated as described previously (GfE, 2001; Schuh et al., 2019).

\section{Current Trial: Metabolic Clustering of Dairy Cows}

Taking advantage of the data from the basic trial, we investigated whether further clustering could be obtained by applying ML. Figure 2 provides an overview of the ML procedures and the main clustering results. Four ML approaches [sequential minimal optimization (SMO), random forest (RF), alternating decision tree (ADTree), and naïve Bayes-updatable (NB)] were applied to the changes (d 21 pp minus d 49 ap) in the concentrations of 170 serum metabolites to calculate the posterior probability $p(y \mid X)$ for each cow, where $y$ is the predicting cow's label (HBCS or NBCS) and $X$ is the cow's given feature vectors (serum metabolite data). To be able to properly evaluate the performance of the ML models, a leave-one-out cross-validation (K-fold cross-validation with $\mathrm{K}=\mathrm{N}$, where $\mathrm{N}$ is the number of samples in the data set) schema was performed. Considering HBCS as positive cases and NBCS as negative ones, the prediction cases were true positives (TP, the number of correctly predicted positives), false predicted positives (FP), truly predicted negatives $(\mathrm{TN})$, and falsely predicted negatives (FN). Accuracy was calculated as follows: accuracy $=(\mathrm{TP}+\mathrm{TN}) /(\mathrm{TP}$ $+\mathrm{TN}+\mathrm{FP}+\mathrm{FN})$.

\section{Statistical Analyses}

The repeated-measures analysis was conducted using the MIXED procedure in SAS (version 9.4; SAS Institute Inc., Cary, NC) to compare the subgroups obtained in terms of feed intake, milk yield, and composition, as well as the classical metabolic variables (FA, BHB, leptin, glucose, insulin, haptoglobin, adiponectin, and RQUICKI). Before analysis, all data were tested for normality of distribution by evaluating the ShapiroWilk statistic using the UNIVARIATE procedure of SAS. When the data were not normally distributed, they were transformed using a $\log _{10}$ transformation. The model consisted of parity, group, time, and interaction of group and time as fixed effects, and cow as the random effect. The SLICE statement of the MIXED 


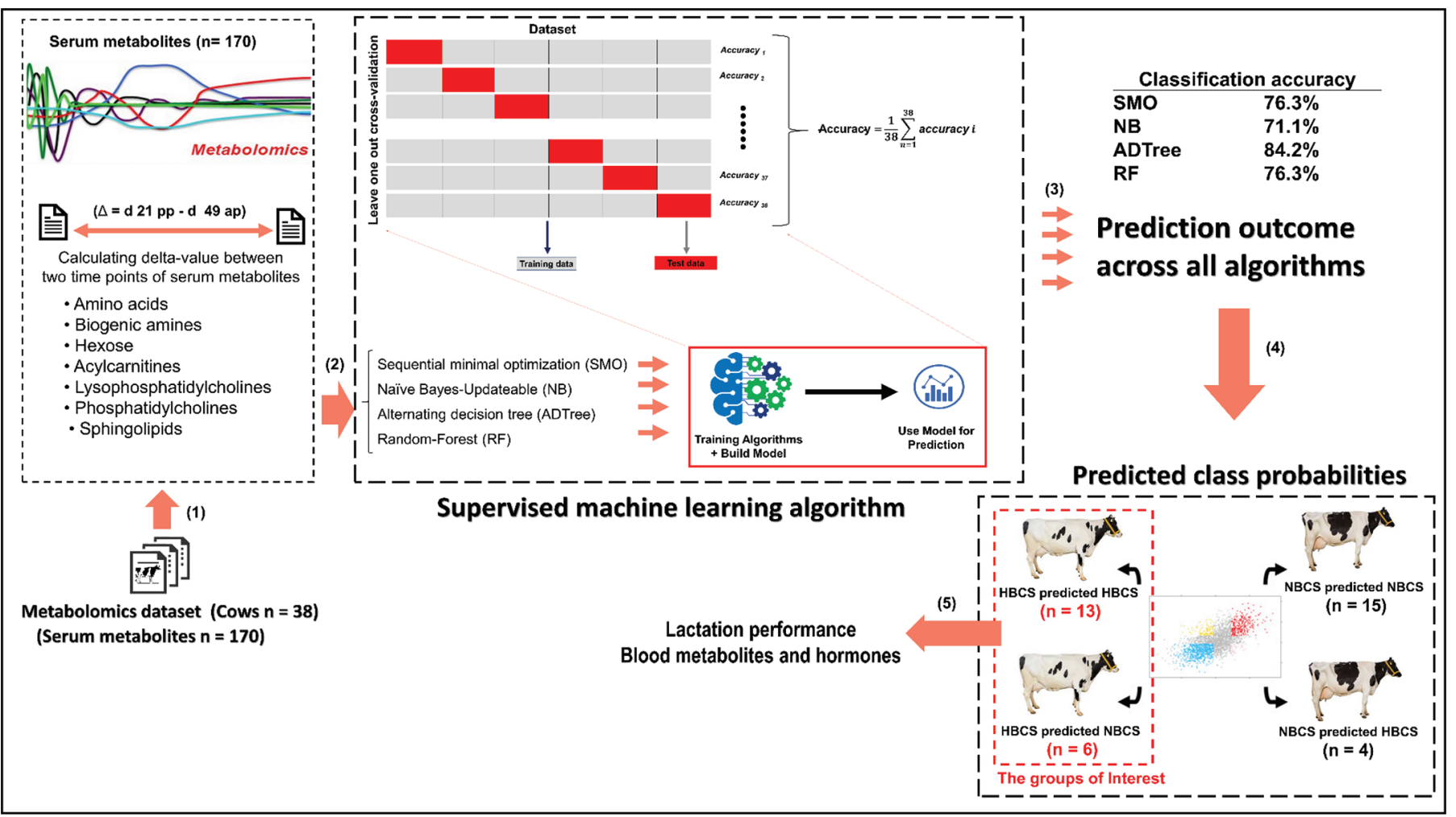

Figure 2. Workflow of machine learning analysis procedures to characterize the metabolic signature of periparturient cows during the experimental period. The basic trial provided 1 group with high BCS (HBCS) and 1 with normal BCS (NBCS), as described by Schuh et al. (2019). Metabolic clustering by applying 4 supervised machine learning-based classifiers [sequential minimal optimization (SMO), random forest (RF), alternating decision tree (ADTree), and naïve Bayes-Updatable (NB)] on the changes in concentrations of 170 serum metabolites [d 21 postpartum (pp) minus d 49 antepartum (ap) resulted in 4 distinct metabolic clusters: HBCS cows predicted high BCS (HBCS-PH, $\mathrm{n}=13$ ), HBCS cows predicted normal (HBCS-PN, $\mathrm{n}=6$ ), NBCS cows predicted normal (NBCS-PN, $\mathrm{n}=15$ ), and NBCS cows predicted high $(\mathrm{NBCS}-\mathrm{PH}, \mathrm{n}=$ 4)]. The accuracies of SMO, RF, ADTree, and NB classifiers were over $70 \%$.

procedure was used to conduct partitioned analyses of the least squares means for interactions (group $\times$ time). All means were compared using the PDIFF statement of SAS. Statistical significance was declared at $P \leq$ 0.05 , and trends were declared at $0.05<P \leq 0.10$.

Statistical analysis of serum metabolite data on d 21 pp was performed using the web tool MetaboAnalyst 4.0 (Chong et al., 2018). Briefly, values lower than the limit of detection were not considered for statistical analysis. Metabolite data $(\mathrm{n}=170)$ were transformed using generalized log transformation and then Pareto scaled to correct for heteroscedasticity, to reduce the skewness of the data and to reduce mask effects (van den Berg et al., 2006). A volcano plot was performed to relate fold change to statistical significance. Important metabolites were selected by the volcano plot based on a fold change threshold of 1.4 on the $\mathrm{x}$-axis and a nonparametric $t$-test threshold ( $P$-value) of 0.1 on the $\mathrm{y}$-axis. The variable importance in projection (VIP) of partial least squares discriminant analysis model was performed using MetaboAnalyst 4.0 to rank metabolites according to their importance in discriminating groups (HBCS predicted high vs. HBCS predicted normal). A heat map was generated based on glycerophospholipids (lyso-, diacyl-, and acyl-alkyl-phosphatidylcholines) and sphingomyelins (SM) using Ward linkage method in MetaboAnalyst 4.0.

\section{RESULTS}

\section{Metabolic Clustering}

Metabolic clustering by applying 4 supervised MLbased classifiers (SMO, RF, ADTree, and NB) on the changes in concentrations (d 21 pp minus d 49 ap) of 170 serum metabolites resulted in 4 distinct metabolic clusters: HBCS predicted HBCS (HBCS-PH, $\mathrm{n}=13$ ), HBCS predicted NBCS (HBCS-PN, $\mathrm{n}=6$ ), NBCS predicted NBCS (NBCS-PN, $\mathrm{n}=15$ ), and NBCS predicted HBCS (NBCS-PH, $\mathrm{n}=4$ ). The accuracies of SMO, RF, ADTree, and NB classifiers were over $70 \%$ (Supplemental Figure S1, https://doi.org/10.3168/jds 
A

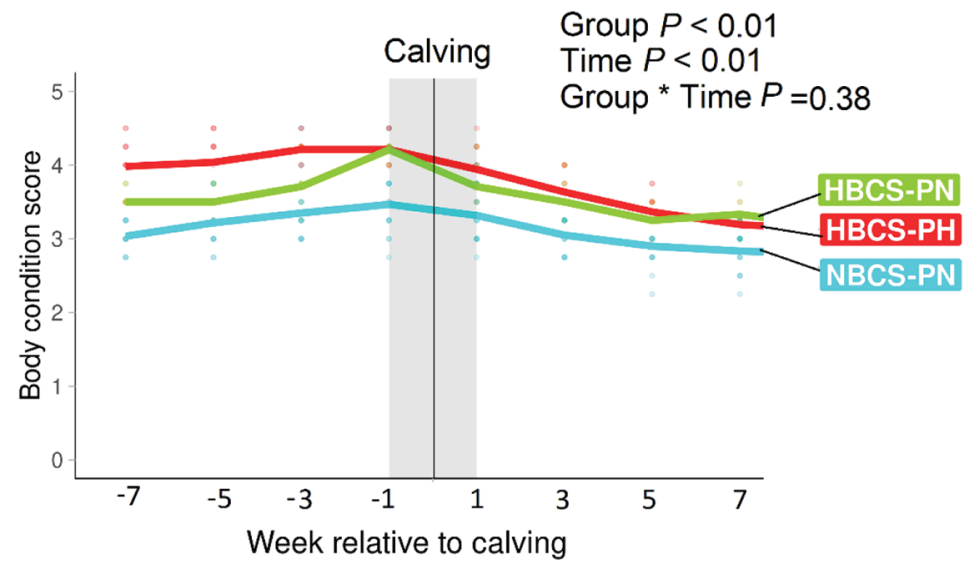

C

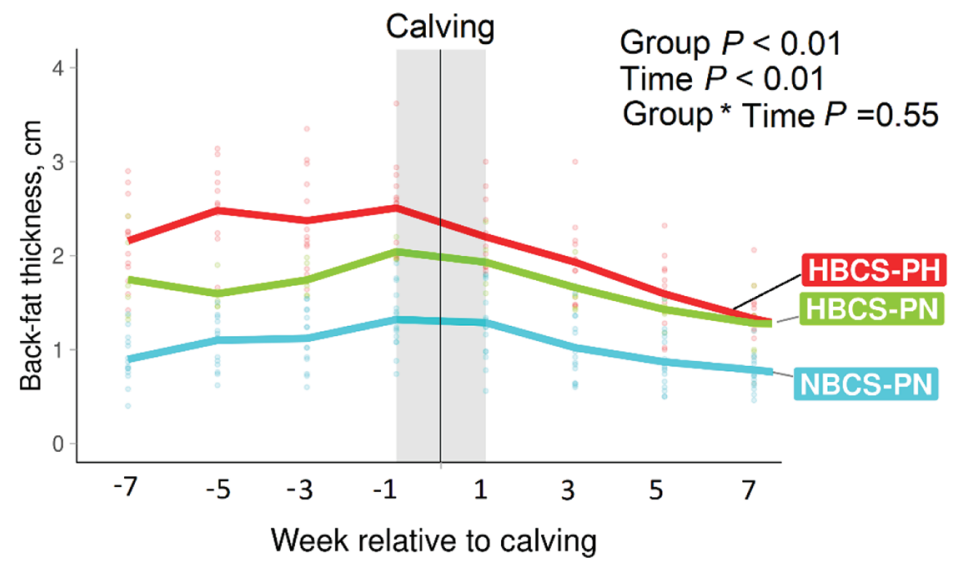

B

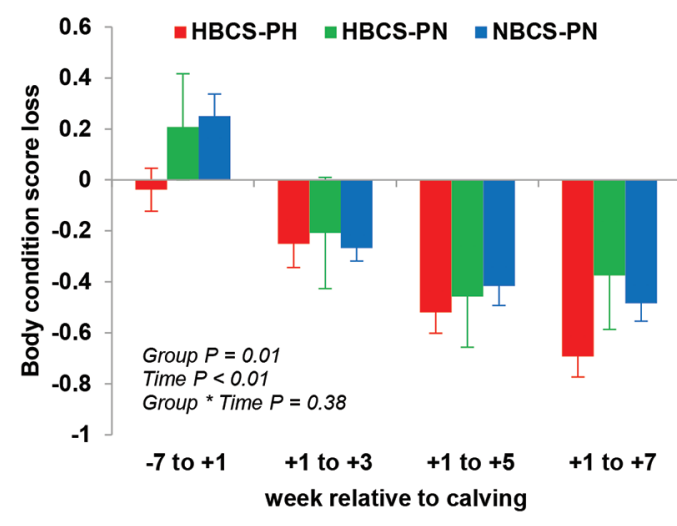

D

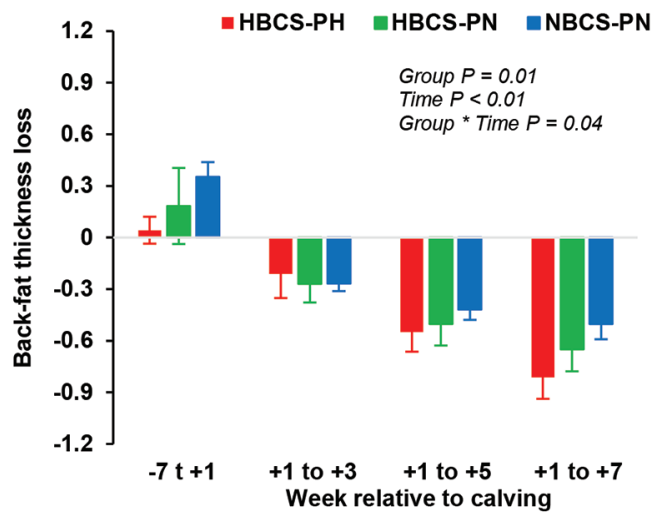

Figure 3. Changes in BCS (A), BCS loss (means \pm SEM, B), backfat thickness (BFT, C), and BFT loss (means \pm SEM, D) of the 3 clusters [high BCS cows predicted high BCS (HBCS-PH, $\mathrm{n}=13$; red), HBCS cows predicted normal (HBCS-PN, $\mathrm{n}=6$; green), and normal BCS cows predicted normal (NBCS-PN, $\mathrm{n}=15$; blue)] from wk -7 until wk +7 relative to calving (panels $\mathrm{A}$ and $\mathrm{C}$ ). Dots indicate individual records, and the vertical line represents the mean.

.2020-18661). Due to the low number of NBCS-PH cows, we did not consider this group for further comparisons.

\section{Production and Metabolic Performance}

Figure 3 shows the changes of BCS (Figure 3A), BCS loss (Figure 3B), BFT (Figure 3C), and BFT loss (Figure 3D) in the 3 clusters HBCS-PH, HBCS-PN, and NBCS-PN from wk 7 ap until wk 7 pp. Higher values for BCS and BFT were observed for HBCSPH cows compared with HBCS-PN cows at wk 7 ap; however, both overconditioned groups had identical body condition around calving [wk -1 (HBCS-PH: $\mathrm{BCS}=4.21 \pm 0.29, \mathrm{BFT}=2.51 \pm 0.49 \mathrm{~cm}$, means $\pm \mathrm{SD}$; HBCS-PN: $\mathrm{BCS}=4.21 \pm 0.09, \mathrm{BFT}=2.04 \pm$ $0.08 \mathrm{~cm}$ ) and $\mathrm{wk}+1$ (HBCS-PH: BCS $=3.94 \pm 0.31$, $\mathrm{BFT}=2.20 \pm 0.38 \mathrm{~cm} ;$ HBCS-PN $: \mathrm{BCS}=3.71 \pm$
$0.39, \mathrm{BFT}=1.93 \pm 0.25 \mathrm{~cm})]$. Body condition score and BFT declined in early lactation (wk $7 \mathrm{pp}$ ) in all groups, but the losses were greater for HBCS-PH cows than for HBCS-PN cows [BCS loss $(\mathrm{wk}+1$ to +7$)=$ -0.69 vs. -0.38 ; BFT loss $(\mathrm{wk}+1$ to +7$)=-0.81$ vs. $-0.65 \mathrm{~cm}]$. Figures $4 \mathrm{~A}$ and $4 \mathrm{~B}$ present the main results of principal component analysis performed using the mean values of 170 metabolites measured in this study, assigned to different metabolic clusters for d 49 ap and d $21 \mathrm{pp}$, respectively. Principal components 1,2 , and 3 respectively explained $45.0 \%, 7.2 \%$, and $5.6 \%$ of the total variance on d 49 ap, and $35.0 \%$, $7.8 \%$, and $7.0 \%$ of the total variance on $\mathrm{d} 21 \mathrm{pp}$. The results from the principal component analysis (Figure $4 \mathrm{~A}, \mathrm{~B}$ ) show that blood metabolites of HBCS-PN cows were much closer to those of NBCS-PN cows, whereas HBCS-PH cows were placed on opposite sides on both d 49 ap and d 21 pp. 
Figure 5 shows the change from d 49 ap to d 21 pp for the serum concentrations of metabolites $(\mathrm{n}=170)$ in the 6 compound classes [acylcarnitines $(\mathrm{AcylCN}), \mathrm{AA}$, biogenic amines, glycerophospholipids (diacyl and acylalkyl), sphingolipids, and lyso-phosphatidylcholines] as fold change (FC, values on d $21 \mathrm{pp}$ divided by values on d 49 ap) in HBCS-PH (Figure 5A) and HBCS-PN (Figure 5B). The largest FC values in HBCS-PH were observed for 3 metabolites belonging to long-chain AcylCN [hexadecanoyl-carnitine (C16), octadecanoylcarnitine (C18), and octadecenoyl-carnitine (C18:1)] and for Gly $(4.5<\mathrm{FC}>3)$. In HBCS-PN, levels of these metabolites also changed but with lesser differences $(3<\mathrm{FC}>1.8)$. Moreover, negative $\mathrm{FC}$ values (pp vs. ap) were observed for glycerophospholipids and SM in HBCS-PN than in HBCS-PH.

The average DMI (as $\mathrm{kg} / \mathrm{d}$ and percentage of BW), milk yield, milk composition, ECM, and EB across all time points of lactation are presented in Table 1 and the time courses in Figure 6, respectively. Dry matter intake as kilograms per day $(P=0.02$, Figure $6 \mathrm{~A})$ and percentage of BW $(P=0.05)$ were greater in HBCS-PN than in HBCS-PH cows, and HBCS-PN also reached a positive EB (Figure 6B) earlier than HBCS-PH. Milk yield (Figure 6C), ECM, and milk composition were not different between groups (HBCS-PN vs. HBCS-PH), except that milk protein percentage was greater $(P<$
0.01) and a tendency to a higher milk fat percentage in HBCS-PN than in HBCS-PH cows.

In both groups, serum concentrations of FA (Figure 7A) increased after calving, but without differences between HBCS-PN and HBCS-PH cows. In contrast, serum concentrations of BHB (Figure 7B) were greater $(P<0.01)$ in HBCS-PH than in HBCS-PN cows during wk 2 to 7 pp. Serum concentrations of leptin (Figure $7 \mathrm{C}$ ), adiponectin (Figure 7D), glucose (Figure 7E), and insulin (Figure 7F) were similar between HBCS-PN and HBCS-PH across all time points.

Supplemental Figure S2 (https://doi.org/10.3168/jds .2020-18661) shows the significant metabolites identified by the volcano plot on d 49 ap. The serum concentrations of 59 metabolites belonging to phosphatidylcholines and SM were lower in HBCS-PH compared with HBCS-PN cows. Figures 8A shows the significant metabolites identified by the volcano plot on d $21 \mathrm{pp}$. The serum concentrations of 9 metabolites belonging to AcylCN [acetylcarnitine (C2), propionyl-carnitine (C3), butyryl-carnitine (C4), C16, C18, C18:1], 2 AA (Gly, Phe), and 1 biogenic amine ( $\alpha$-aminoadipic acid) were greater in HBCS-PH compared with HBCS-PN cows. Similar metabolites, as well as octadecadienylcarnitine (C18:2) and tiglyl-carnitine (C5:1), were detected by VIP score (VIP > 2) on d 21 pp (Figure 8b). According to VIP scores, long-chain AcylCN (C18

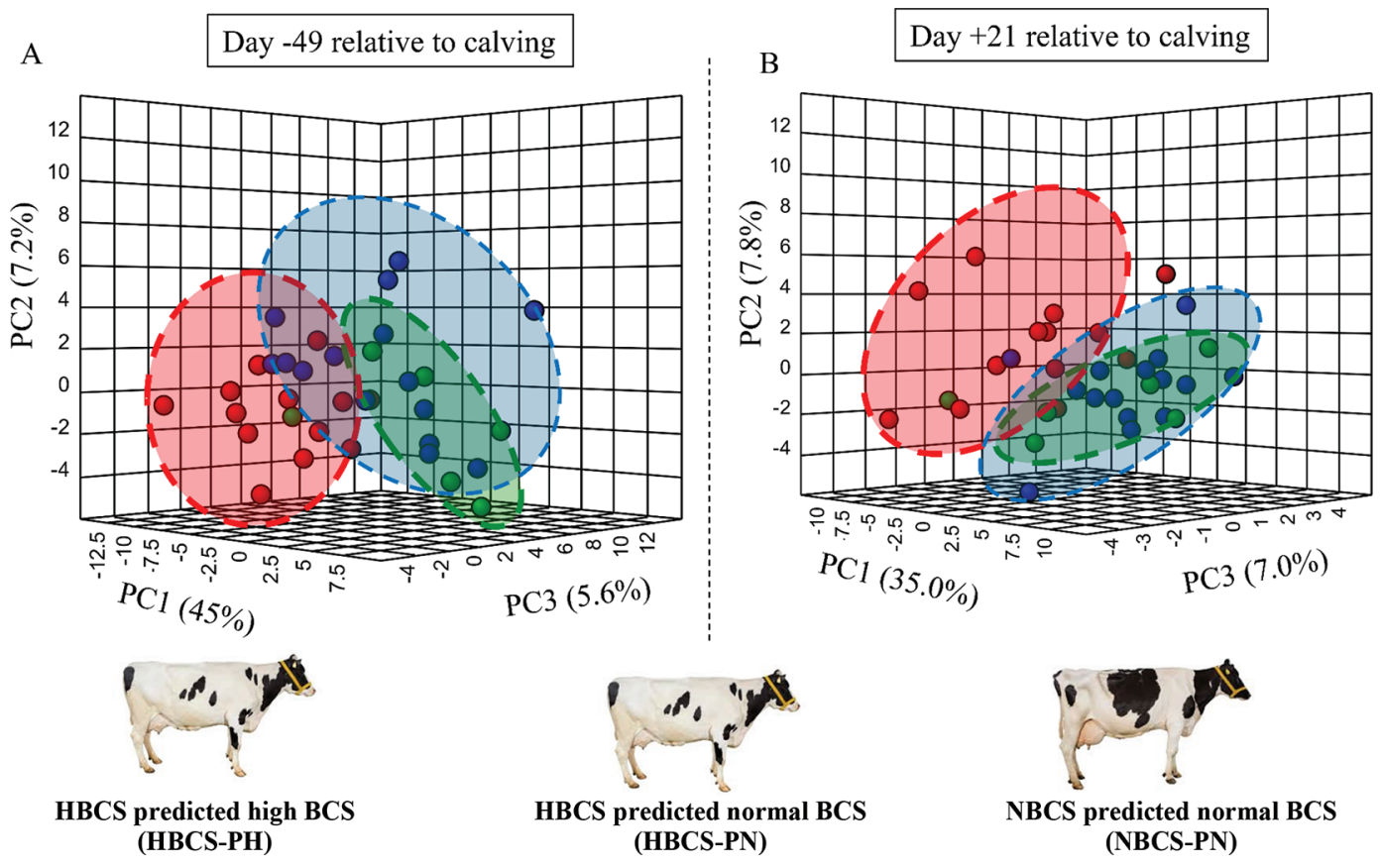

Figure 4. The principal component $(\mathrm{PC})$ analysis plot of serum metabolites $(\mathrm{n}=170)$ measured in this study subjected to 3 clusters $[$ highBCS cows predicted high (HBCS-PH, $\mathrm{n}=13$ ), high-BCS cows predicted normal (HBCS-PN, $\mathrm{n}=6$ ), and normal BCS cows predicted normal (NBCS-PN, $\mathrm{n}=15)$ ] on $\mathrm{d}-49(\mathrm{~A})$ and $\mathrm{d}+21(\mathrm{~B})$ relative to calving. 


\section{A HBCS-PH}

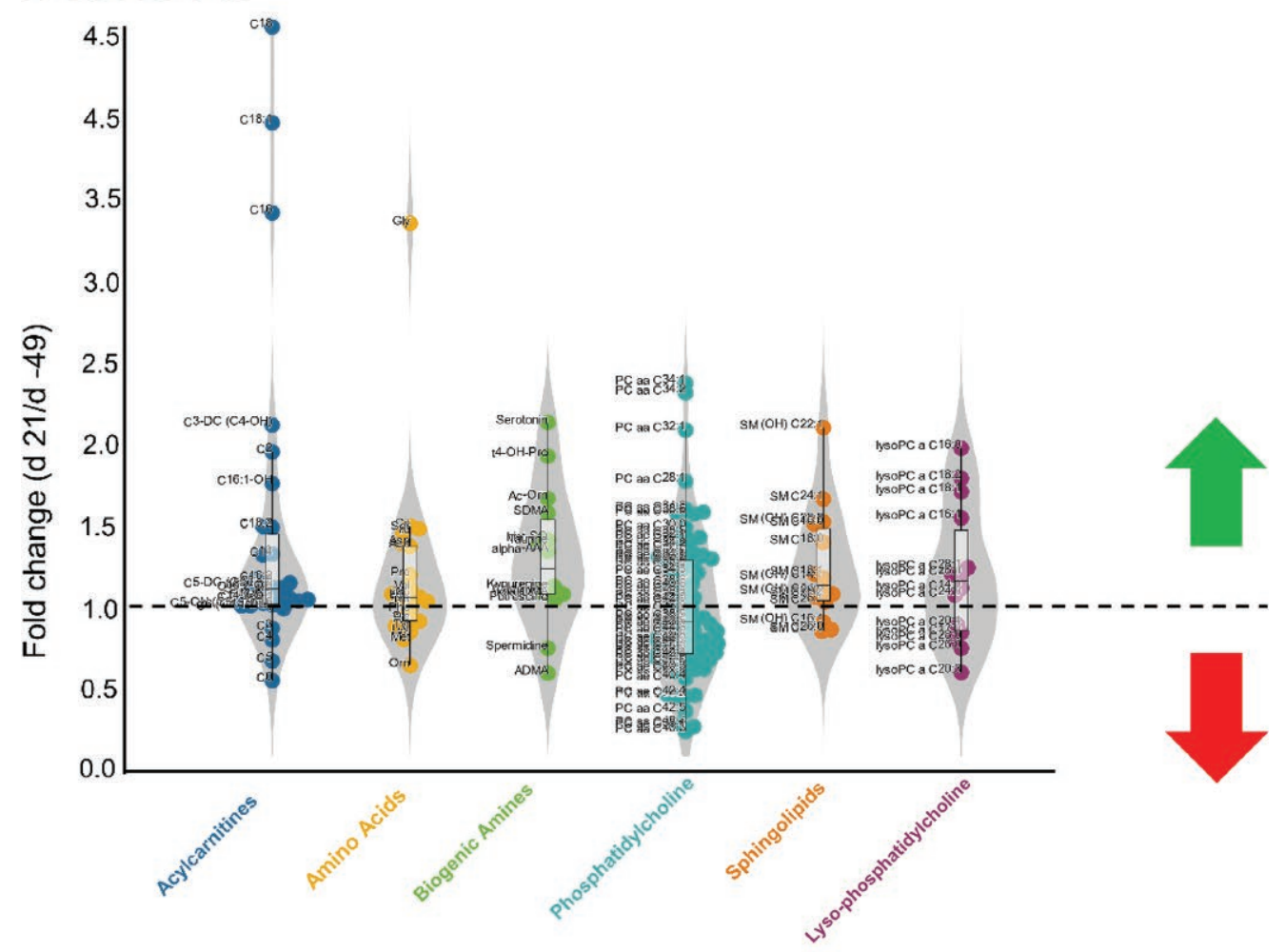

\section{B HBCS-PN}

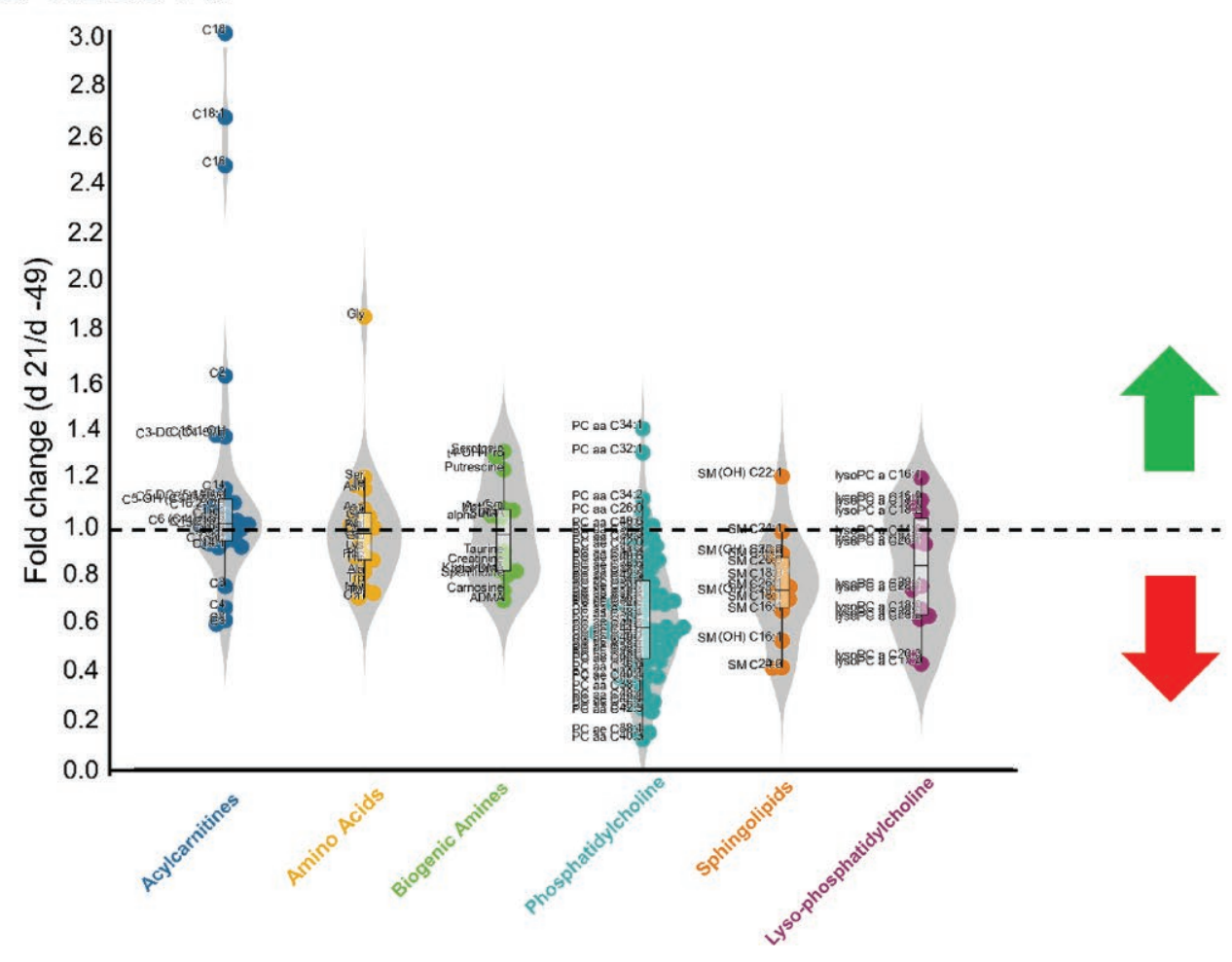

Figure 5. Changes relative to calving in relative concentrations of serum metabolites $(\mathrm{n}=170)$ in 6 compound classes [acylcarnitines (AcylCN), amino acids, biogenic amines, glycerophospholipids (diacyl and acyl-alkyl), sphingolipids, and lyso-phosphatidylcholines] in highBCS cows predicted high (A, HBCS-PH, $\mathrm{n}=13$ ) and high-BCS cows predicted normal (B, HBCS-PN, $\mathrm{n}=6$ ) from d 49 antepartum to $\mathrm{d} 21$ postpartum. Fold change was calculated as the ratio of means from d 21 postpartum to d 49 antepartum. 
Table 1. The average of DMI, NE $\mathrm{L}_{\mathrm{L}}$, milk yield, milk composition, ECM, and energy balance (EB) in overconditioned cows predicted high BCS (HBCS-PH, $\mathrm{n}=13$ ) and overconditioned cows predicted normal BCS (HBCS-PN, $\mathrm{n}=6$ ) from wk 2 to 14 postpartum

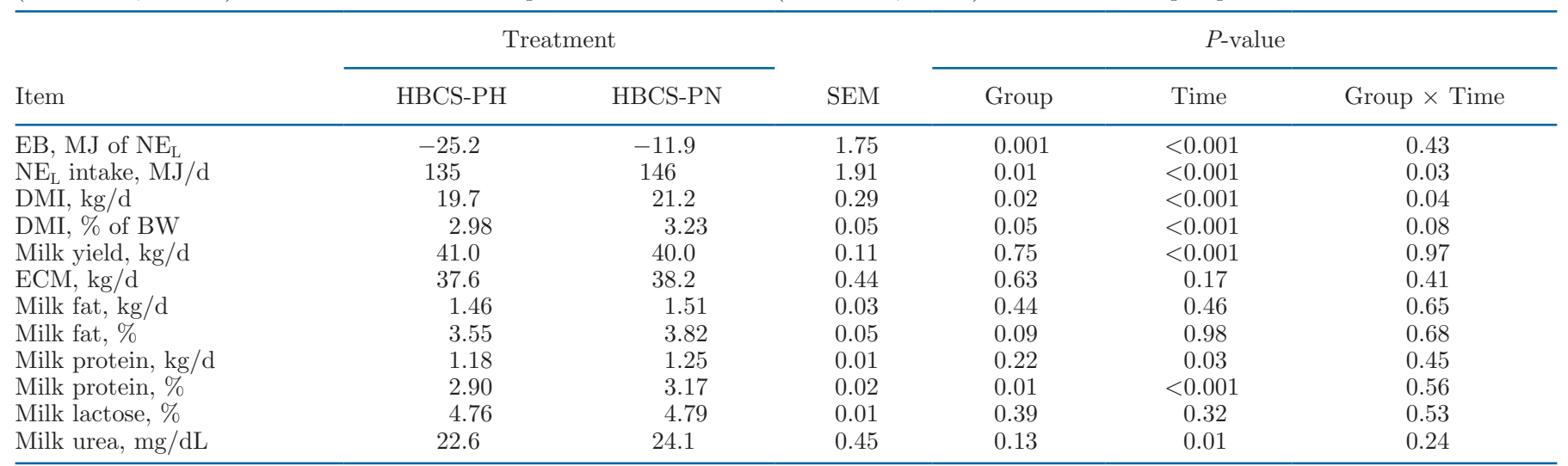

\section{HBCS-PN $\square$ HBCS-PH}

A

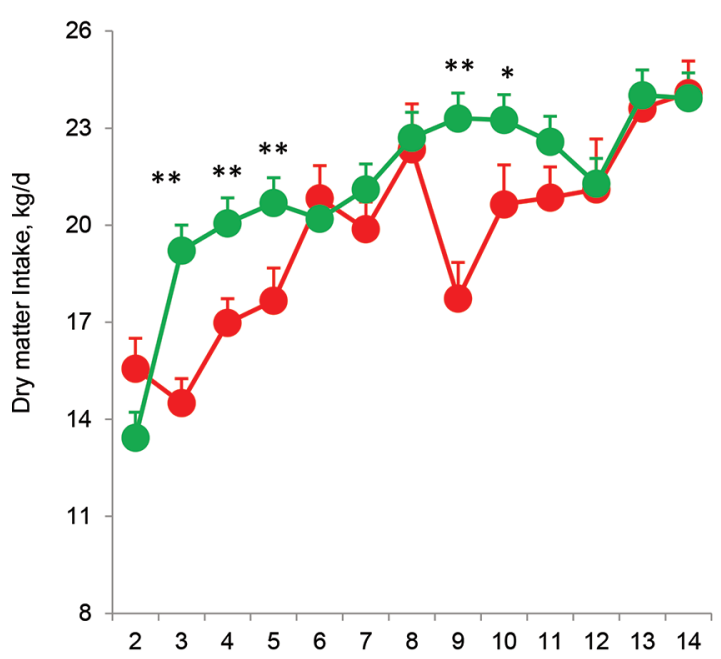

$\mathrm{C}$

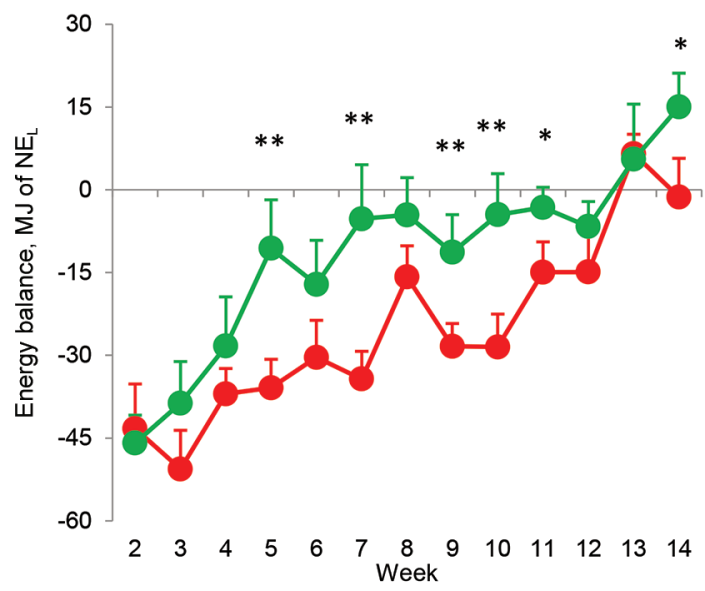

B

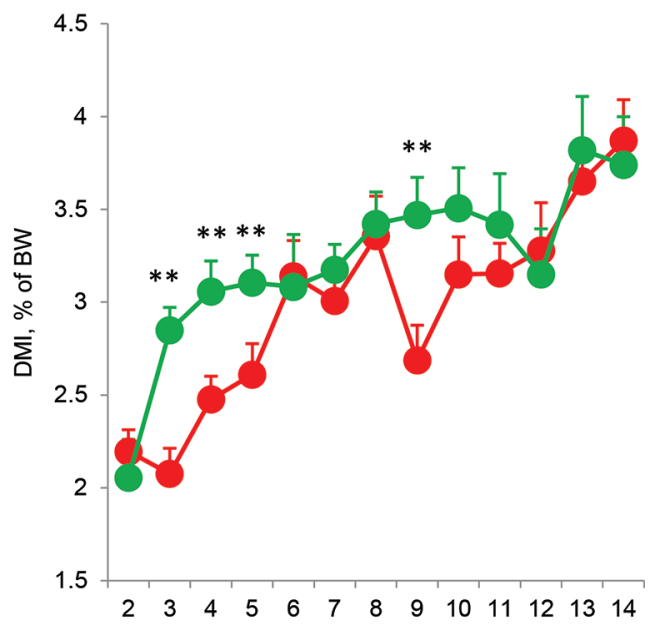

D

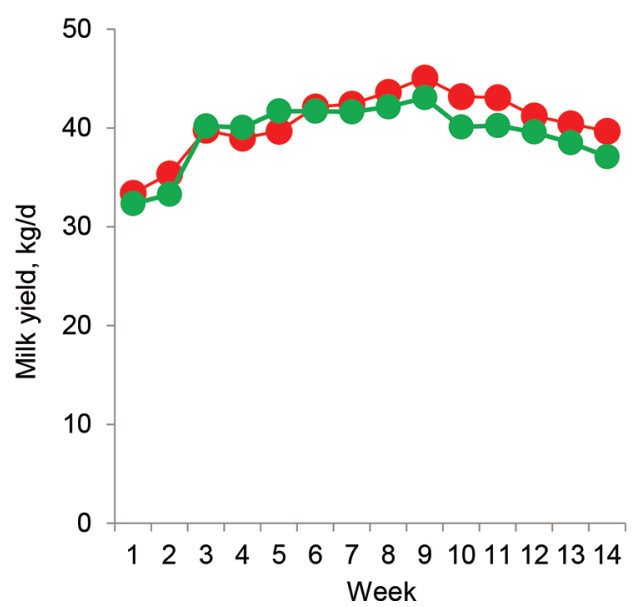

Figure 6. Time course of DMI as kilograms per day (A), and DMI as a percentage of body weight (B), energy balance (C), and milk yield (D) of high-BCS cows predicted high (HBCS-PH, $\mathrm{n}=13$ ) and high-BCS cows predicted normal (HBCS-PN, $\mathrm{n}=6$ ) during the experiment. Asterisks indicate significant differences between the groups at a given time point $\left({ }^{*} P<0.05 ;{ }^{* *} P<0.01\right)$. Data are presented as mean \pm SEM. 
and C16) and Gly were the top metabolites affected by group (HBCS-PH vs. HBCS-PN). The serum concentrations of AcylCN are shown in Figure 9. Serum concentrations of $\mathrm{C} 2, \mathrm{C} 3, \mathrm{C} 4, \mathrm{C} 12, \mathrm{C} 16: 0, \mathrm{C} 18: 0$, and C18:1 were greater $(P<0.05)$ in HBCS-PH than in HBCS-PN cows on d 21 pp. A heat map of relative levels of glycerophospholipids and SM in serum on d 49 ap and d $21 \mathrm{pp}$ is shown in Figure 10. The relative serum levels of glycerophospholipids and SM were lower in HBCS-PH compared with HBCS-PN and NBCS-PN on d 49 ap. However, on d $21 \mathrm{pp}$, the observed differences between HBCS-PH and HBCS-PN largely disappeared, and both groups of overconditioned cows had lower serum levels of glycerophospholipids compared with NBCS-PN cows.

\section{DISCUSSION}

\section{Metabolic Clustering}

In the current study, we followed the idea that the variation in the metabolic profiles obtained during the transition period would allow for identifying clusters of cows within groups predefined according to body condition. Intrigued by the concept of $\mathrm{MHO}$ from human medicine (Blüher, 2020), we aimed to test whether divergent metabotypes could be identified within a cohort of overconditioned cows. The metabolomic profiles of such clusters might be predictive for certain metabolic trajectories and pathophysiological states.

Using different ML algorithms, we were able to identify a cluster (HBCS-PN) of cows with different metabolic phenotypes compared with HBCS-PH but close to NBCS-PN cows. We refrain from designating these HBCS-PN cows as MHO because we cannot define health status comparably to human patients, in whom not only metabolic traits but also cardiovascular states are recorded. When comparing the incidence of diseases in NBCS and HBCS groups in earlier works (Ghaffari et al., 2020), metabolic diseases (hypocalcemia and ketosis) tended $(P=0.08)$ to be more frequent in HBCS than in NBCS cows (28\% vs. $15 \%)$. For the current comparison of HBCS-PN versus HBCS-PH (Supplemental Table S1, https://doi.org/10.3168/jds .2020-18661), the numbers of cases of ketosis and milk fever were, respectively, 3 and 5 among HBCS-PH, versus 0 and 1 in the HBCS-PN cows. However, the sample size in our study was certainly too limited for valid comparisons of disease incidence. We therefore prefer to use the term MBO for the HBCS-PN cows. Metabolic imbalance in dairy cows was defined as a situation in which the capacity to cope with metabolic stress is insufficient for optimal function and imposes an increased risk for developing metabolic as well as infectious diseases (Ingvartsen, 2006). The variables that are presently being used to classify a cow as metabolically balanced or imbalanced comprise elevated blood concentrations of FA, ketone bodies, long-chain AcylCN (Rico et al., 2018; Yang et al., 2019; Ghaffari et al., 2020), and ceramides (Rico et al., 2015; Davis et al., 2019; McFadden and Rico, 2019) in combination with reduced concentrations of IGF-I and glucose (Ingvartsen et al., 2003; De Koster et al., 2019), and glycerophospholipids (Ghaffari et al., 2019). However, no unifying established definition for MBO exists yet.

\section{Performance and Metabolism}

Dairy cows undergo a series of homeorhetic mechanisms, such as changes in energy partitioning toward the mammary gland, when entering lactation (Drackley, 1999). The increase in DMI in early lactation lags behind the rapid increase in milk production, which causes a state of negative EB (Grummer et al., 2004). In the current study, both groups of overconditioned cows experienced negative EB in early lactation, but the calculated EB was less negative in HBCS-PN than in HBCS-PH cows during the first 12 wk of lactation. These differences in EB were attributable to DMI rather than milk yield, because neither milk nor ECM yield differed between the groups.

Overconditioned cows at parturition are less successful in adapting their metabolism to negative EB and mobilize body fat reserves more intensely than do cows at normal body condition in early lactation (Roche et al., 2009; Schulz et al., 2014). In the current study, neither BCS nor BFT differed between the 2 overconditioned clusters 1 wk before (HBCS-PH: BCS $=4.21 \pm$ $0.29, \mathrm{BFT}=2.51 \pm 0.49 \mathrm{~cm}$, mean $\pm \mathrm{SD}$; HBCS-PN: $\mathrm{BCS}=4.21 \pm 0.09, \mathrm{BFT}=2.04 \pm 0.08 \mathrm{~cm})$ and $1 \mathrm{wk}$ after calving (HBCS-PH: BCS $=3.94 \pm 0.31, \mathrm{BFT}=$ $2.20 \pm 0.38 \mathrm{~cm}$; HBCS-PN: BCS $=3.71 \pm 0.39$, BFT $=$ $1.93 \pm 0.25 \mathrm{~cm}$ ), thus supporting the notion that these variables describing body condition may mantle different metabotypes that progress to MBO or metabolic imbalance and may require different management.

We have recently reported that, both ap and pp, HBCS cows had lower serum concentrations of glycerophospholipids than did NBCS cows (Ghaffari et al., 2019). In the current study, we found that HBCS-PN cows were more distinct from HBCS-PH cows but similar to NBCS-PN cows with regard to circulating concentrations of glycerophospholipids only before calving (d 49 ap). Although HBCS-PH cows had lower circulating levels of most species of glycerophospholipids during the dry period compared with HBCS-PN cows, both overconditioned groups had lower circulating levels of glycerophospholipids compared with NBCS-PN 
HBCS-PN $\square$ HBCS-PH
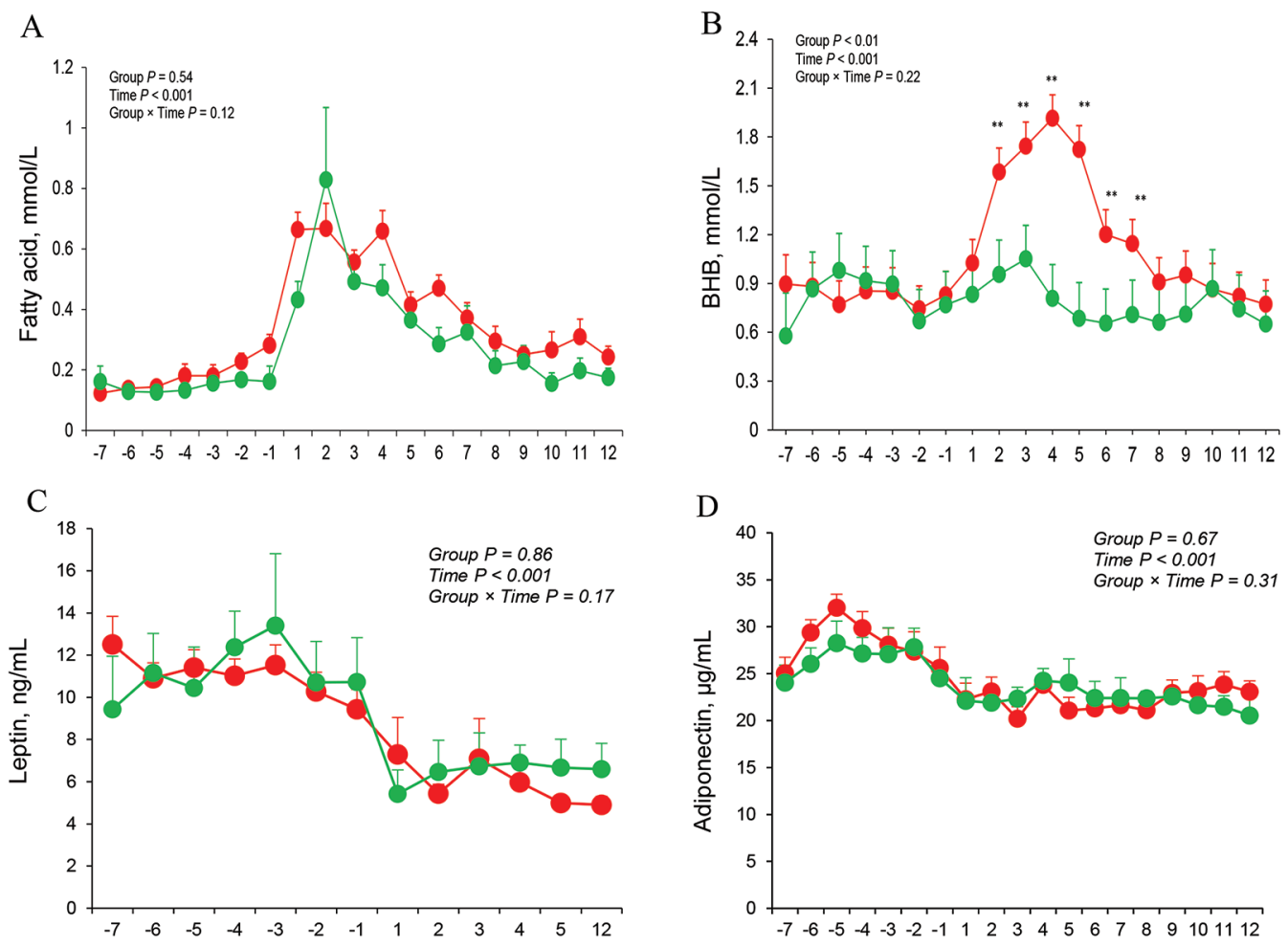

$\mathrm{D}$

$\mathrm{E}$
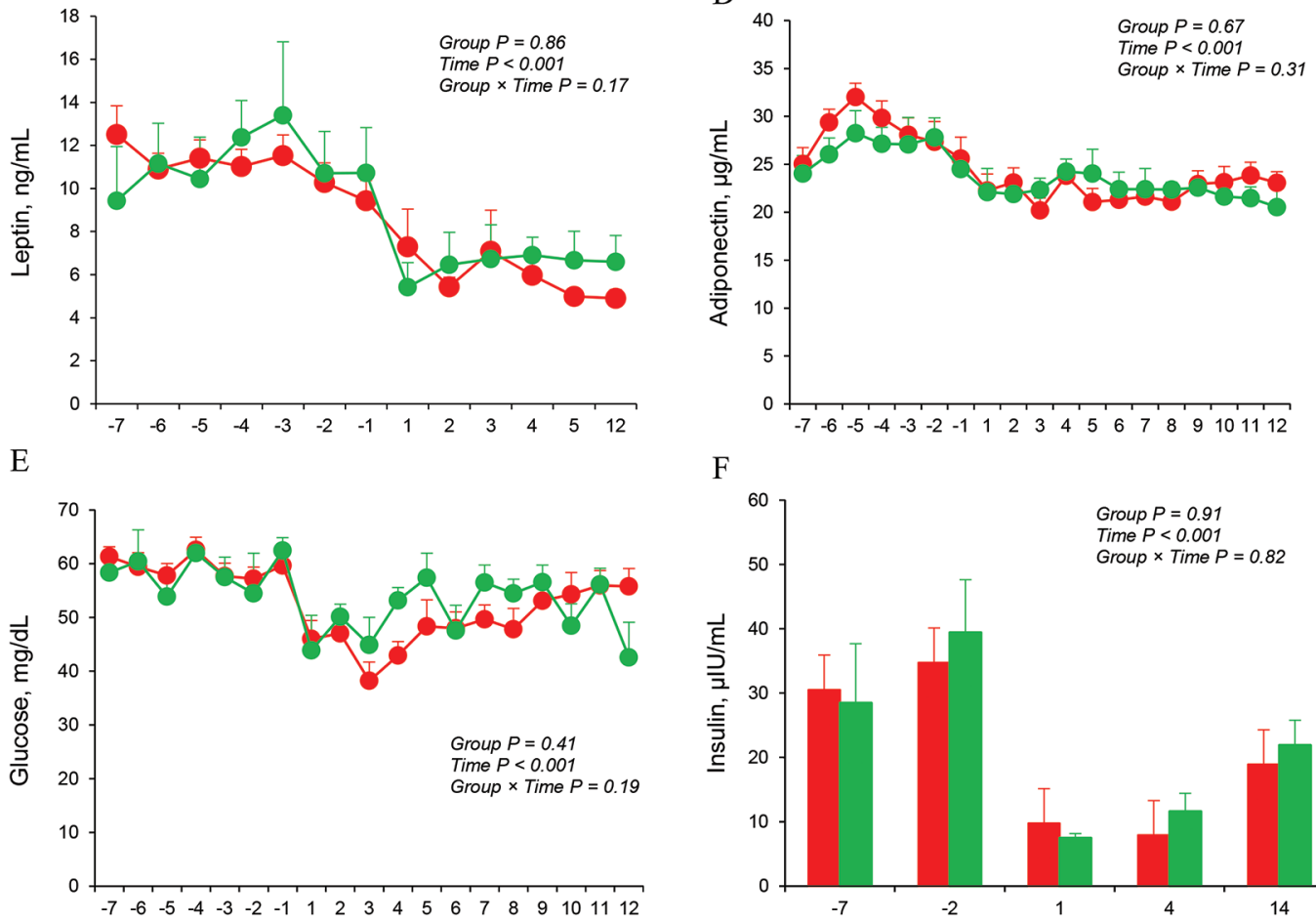

$\mathrm{F}$
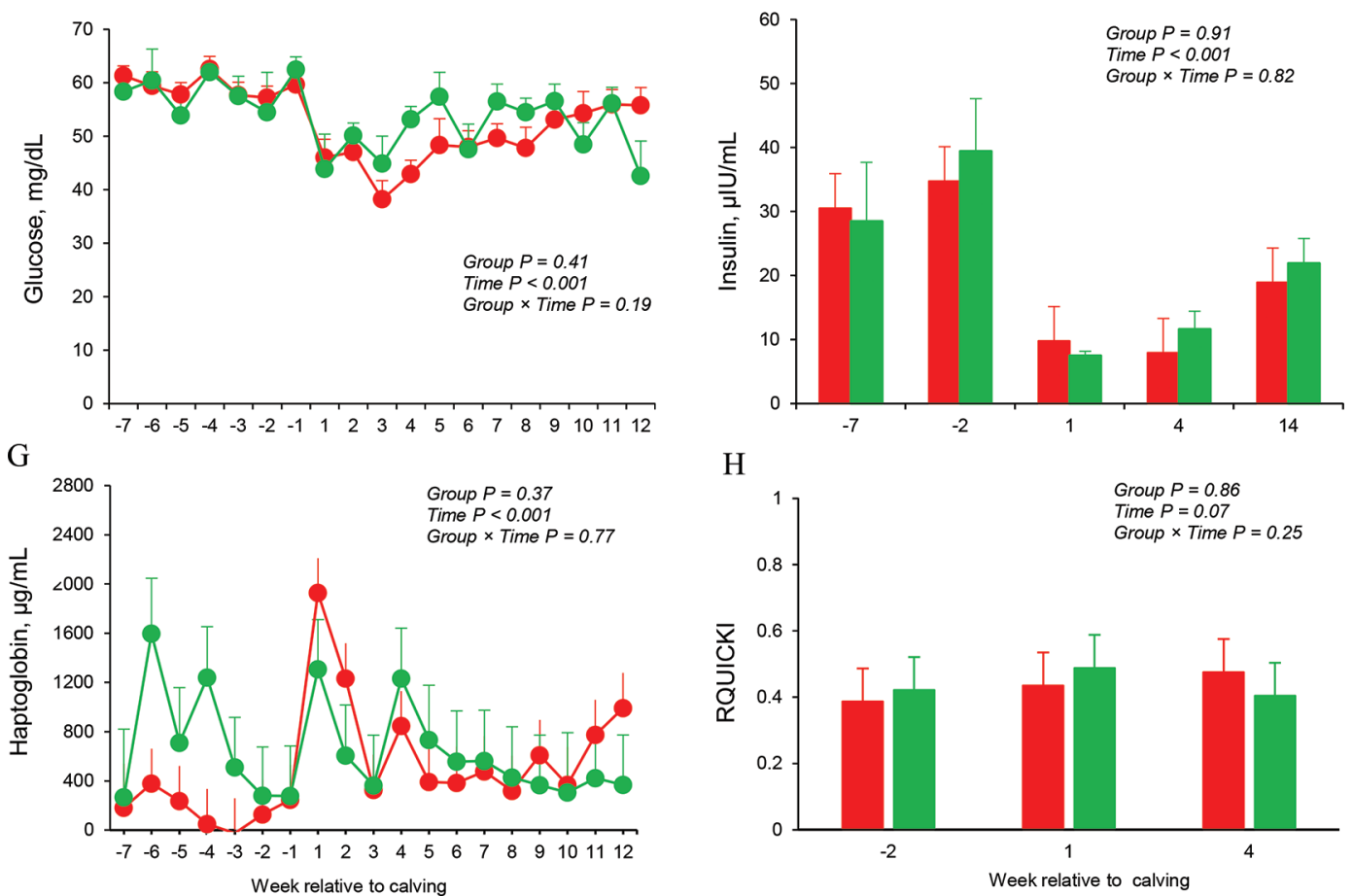

Figure 7. Time course of the concentrations of fatty acids (A), BHB (B), leptin (C), adiponectin (D), glucose (E), insulin (F), haptoglobin $(\mathrm{G})$, and revised quantitative insulin sensitivity check index (RQUICKI, H) of high-BCS cows predicted high $(\mathrm{HBCS}-\mathrm{PH}, \mathrm{n}=13)$ and high-BCS cows predicted normal (HBCS-PN, $\mathrm{n}=6$ ) during the observation period. Data are presented as mean \pm SEM. 

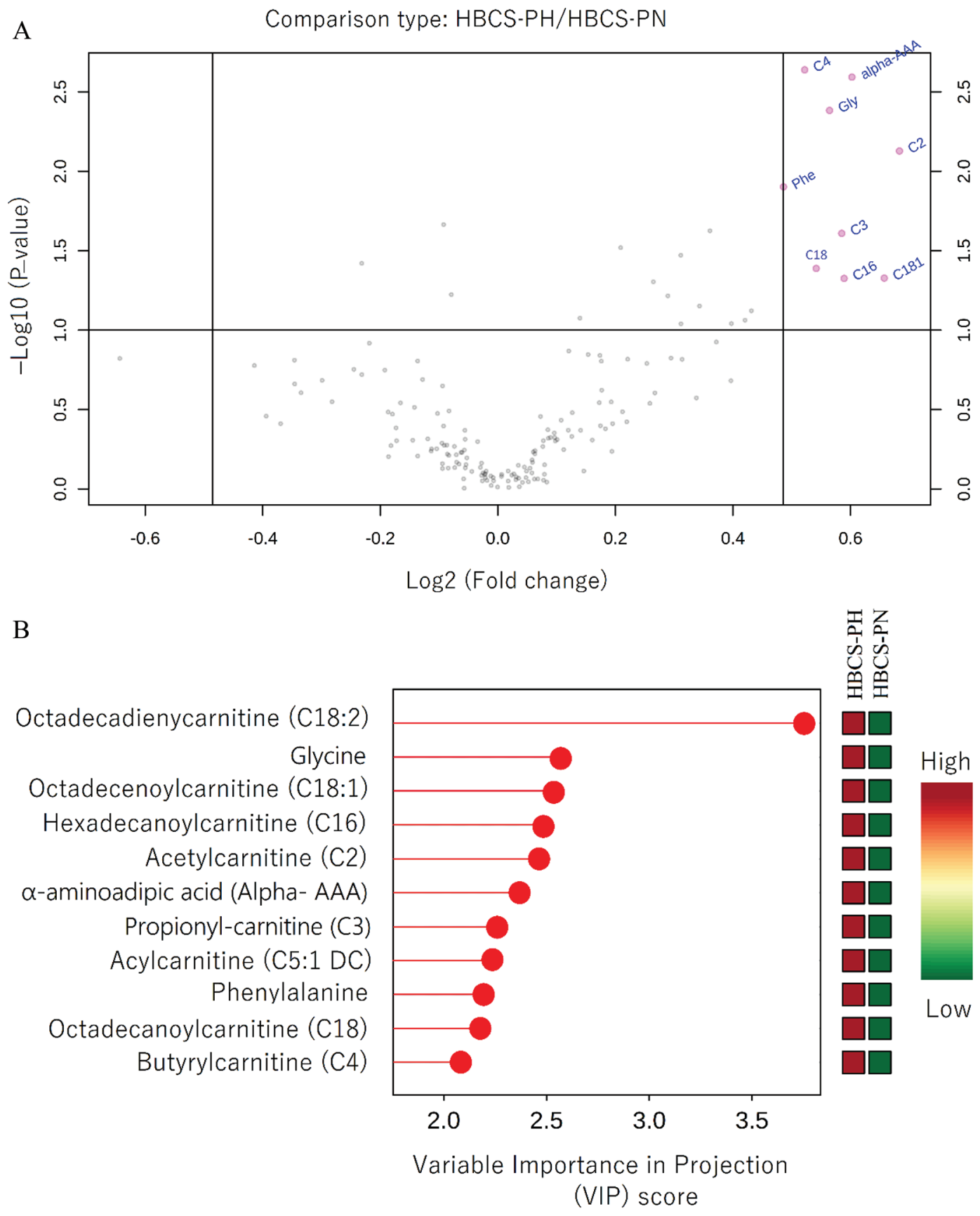

Figure 8. Significant metabolites identified by (A) volcano plot and (B) variable importance in projection (VIP) score (VIP > 2) of partial least squares discriminant analysis model between high-BCS cows predicted high (HBCS-PH, $\mathrm{n}=13$ ) and high-BCS cows predicted normal (HBCS-PN, $\mathrm{n}=6)$ on d 21 postpartum.

cows after calving (d $21 \mathrm{pp})$. Glycerophospholipids are important for very low density lipoprotein synthesis in the liver, thus playing a key role in triglyceride export by the liver (Cole et al., 2012). In this study, the circulating FA concentrations in both HBCS cow clusters increased after calving, pointing to an increased rate of lipid mobilization from tissue reserves. This is fur- ther supported by several changes observed in serum glycerophospholipids. The accumulation of triglycerides in the liver is directly related to circulating FA concentrations (Yuan et al., 2012). Thus, it is likely that a large influx of FA into the liver accompanied by a reduced level of hepatic glycerophospholipids might lead to a greater accumulation of triglycerides in the liver 


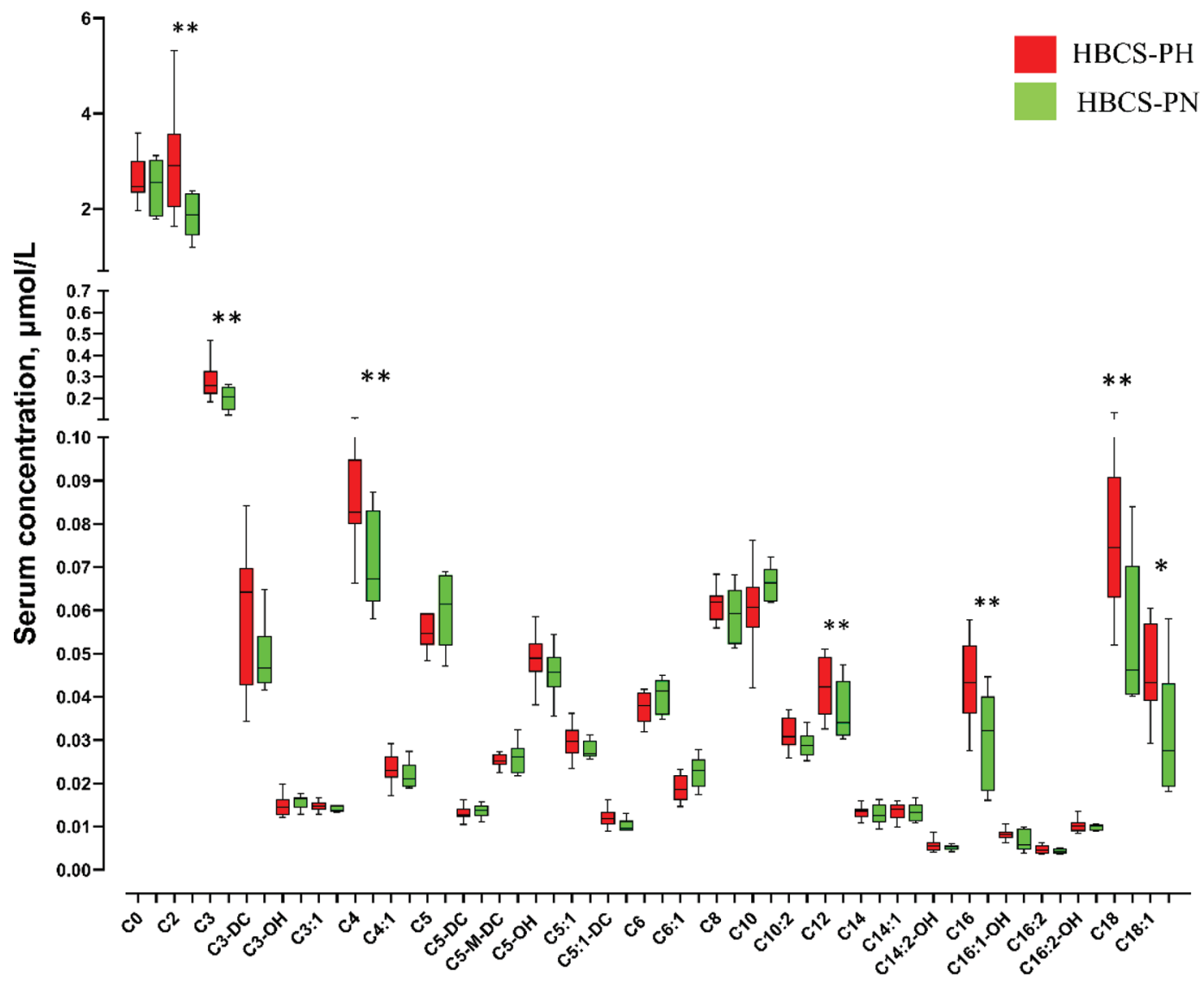

Figure 9. Acylcarnitine (C2 to C18) concentrations in serum of high-BCS cows predicted high (HBCS-PH, $\mathrm{n}=13)$ and high-BCS cows predicted normal (HBCS-PN, $\mathrm{n}=6$ ) on d 21 postpartum. In each box plot, the thick horizontal line crossing the box is the median, the bottom and top of the box are the lower and upper quartiles, and the whisker lengths correspond to 1.5 times the interquartile range (i.e., the distance between the upper and lower quartiles) for both whiskers. Asterisks indicate significant differences $\left({ }^{*} P<0.05 ;{ }^{*} P<0.01\right)$ between the groups.

of both groups of HBCS (HBCS-PH and HBCS-PN) cows. Unfortunately, the liver triglyceride and glycerophospholipids levels of cows have not been assessed in the current study.

Despite increased lipolysis observed in both HBCS groups, demonstrated by elevated circulating FA concentrations, ketogenesis, as indicated by greater BHB concentrations, was clearly more pronounced in the HBCS-PH cows than in the HBCS-PN group. Cows with excessive ketogenesis are prone to clinical or subclinical ketosis in early lactation (Roche et al., 2013). The difference in serum concentrations of BHB but not of FA points toward a decreased capacity of HBCS-PH cows for FA oxidation and thus a shift of lipid metabolism toward ketogenesis and possibly also hepatic triglycerogenesis. In line with decreased FA oxidation in HBCS-PH cows, greater AcylCN concentrations were observed on d $21 \mathrm{pp}$ in these cows compared with HBCS-PN cows, as identified by the volcano plot and partial least squares discriminant analysis VIP scores. Acylcarnitines are incompletely oxidized intermediates of FA and AA generated from the conversion of acylCoA species both in mitochondria and in peroxisomes (Newgard, 2012). Short-chain AcylCN are mainly synthesized from AA and FA (Makrecka-Kuka et al., 2017). Propionylcarnitine (C3) is a potential substrate for odd-chain FA synthesis (Crown et al., 2015) and was identified as a promising biomarker for discriminating metabolic wellness in obesity, independently of body mass index in humans (Gao et al., 2016). Greater levels of C3 were observed in metabolically unhealthy individuals, independent of their body mass index (Batch et al., 2013). Consistent with these observations, the HBCS-PH cows in our study also had greater C3 serum concentrations and thus were likely in an imbalanced metabolic status, compared with the HBCS-PN cows. In addition, the serum concentrations of $\mathrm{C} 2$ on $\mathrm{d} 21$ pp were greater in HBCS-PH than in HBCS-PN cows, accompanied by elevated concentrations of the longchain AcylCN species C16:0, C18, and C18:1 in serum. Acetylcarnitine $(\mathrm{C} 2)$ is the universal degradation product of all metabolites derived from acetyl-CoA by the 
action of carnitine acetyltransferase (Flanagan et al., 2010). These results point to elevated but incomplete FAO in early lactation in HBCS-PH compared with HBCS-PN cows, exceeding the capacity of the downstream metabolic pathways such as the TCA cycle (tricarboxylic acid cycle) and the electron transport chain.

An interesting finding of the present study was the elevated concentration of Gly in the serum of HBCS-PH compared with HBCS-PN cows after calving. Glycine has been recognized as a relevant plasma marker for metabolic disorders associated with obesity in humans (Alves et al., 2019). Plasma Gly concentrations were previously shown to increase after parturition (Zhou et al., 2016a,b) and were greater in high-lipid-mobilizing cows compared with low-mobilizing cows (Humer et al., 2016). The elevated plasma concentration of Gly after parturition may result from an increase in muscle protein breakdown (Doepel et al., 2002) or from choline

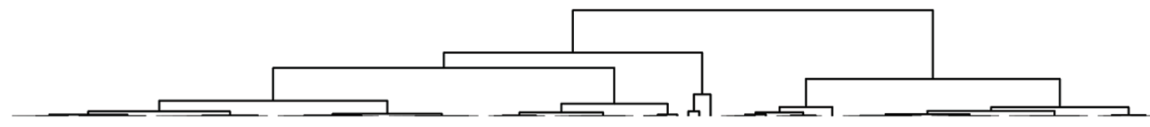

\section{Glycerophospholipids and Sphingomyelins $\mathrm{n}=105$}

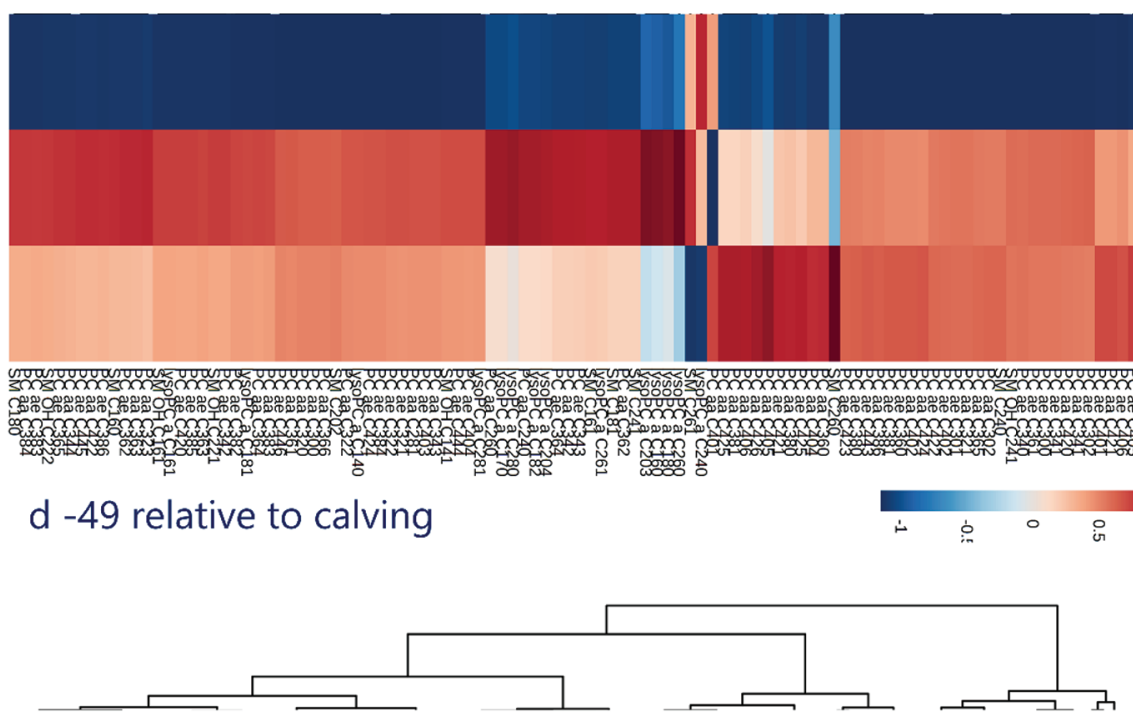

HBCS-PH

HBCS-PN

NBCS-PN

\section{Glycerophospholipids and Sphingomyelins n = 105}

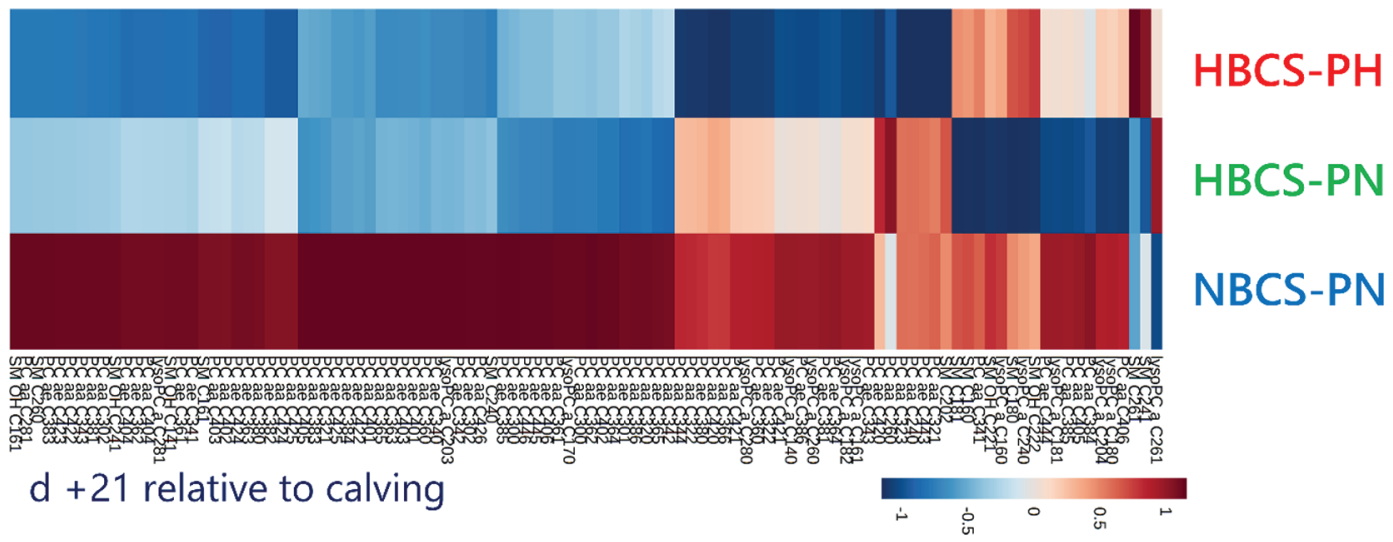

Figure 10. Heat map of serum metabolites illustrating serum glycerophospholipids (lyso-, diacyl-, and acyl-alkyl-phosphatidylcholines) and sphingomyelins in high-BCS cows predicted high (HBCS-PH, $\mathrm{n}=13$ ), high-BCS cows predicted normal (HBCS-PN, $\mathrm{n}=6$ ), and normal-BCS cows predicted normal (NBCS-PN, $\mathrm{n}=15$ ) on $\mathrm{d}-49$ antepartum and $\mathrm{d} 21$ postpartum. The colors in the heat map reflect serum metabolite abundance (mean cantered and divided by the range of each variable). 
degradation (Zhou et al., 2016a). Further research on the underlying pathophysiological mechanisms associated with Gly utilization in overconditioned cows is warranted. We found that circulating concentrations of alpha-aminoadipic acid ( $\mathbf{\alpha - A A A})$ were significantly increased in HBCS-PH compared with HBCS-PN cows. Alpha-aminoadipic acid is an intermediate in the degradation of lysine. Previous studies in rats and humans showed that the plasma concentration of $\alpha$-AAA was increased in the prediabetic phase, and $\alpha$-AAA may thus serve as a marker of diabetes risk (Wijekoon et al., 2004; Wang et al., 2013). Moreover, $\alpha$-AAA has been suggested as a potential marker for oxidative stress (Zeitoun-Ghandour et al., 2011). It is currently unknown whether these relationships apply for dairy cows as well; we did not see differences in oxidative stress markers and insulin sensitivity (assessed by the surrogate index RQUICKI) when comparing HBCS-PH versus HBCS-PN as well as HBCS versus NBCS cows (Ghaffari et al., 2019; Schuh et al., 2019).

Our understanding of MBO cows remains in its infancy, and we do not know the stability of this phenotype over time in dairy cows. In view of the references indicating that MHO status in humans might be only transient and could develop toward unhealthy conditions (Appleton et al., 2013; Soriguer et al., 2013), similar considerations about the concept of MBO in dairy cows may stand to reason. However, given the transient nature of the transition period as such, focusing on this time seems more important than extending research to later lactational stages and future lactations. Moreover, although we have too small a sample size in the cluster of cows found in the NBCS group that had unbalanced or overconditioned features (NBCS-PH), identifying such animals is of particular relevance.

\section{CONCLUSIONS}

Using ML algorithms and serum metabolomics data, we identified a cluster of cows out of a group of overconditioned cows (HBCS-PN) that showed characteristics for having an MBO phenotype. These HBCS-PN cows had greater feed and energy intakes but equal milk yields with higher protein percentage compared with HBCS-PH, resulting in less negative EB. The results indicate that classifying dairy cows as overconditioned by BCS and BFT alone may not be sufficient to adequately consider the needs of all individuals, such as in management and feeding. Further studies are needed for a better understanding of the main determinants for a balanced metabolic status in overconditioned as well as in normal and lean cows.

\section{ACKNOWLEDGMENTS}

The scholarship for K. Schuh by the H. Wilhelm Schaumann Foundation (Hamburg, Germany) is gratefully acknowledged. The study would not have been possible without the Educational and Research Centre for Animal Husbandry, Hofgut Neumühle (Münchweiler an der Alsenz, Germany); they made the cows available, and their staff supported the animal trial. The authors have no conflicts of interest to declare.

\section{REFERENCES}

Alves, A., A. Bassot, A. L. Bulteau, L. Pirola, and B. Morio. 2019. Glycine metabolism and its alterations in obesity and metabolic diseases. Nutrients 11:1356. https://doi.org/10.3390/nu11061356.

Appleton, S. L., C. J. Seaborn, R. Visvanathan, C. L. Hill, T. K. Gill, A. W. Taylor, R. J. Adams, and North West Adelaide Health Study Team. 2013. Diabetes and cardiovascular disease outcomes in the metabolically healthy obese phenotype: A cohort study. Diabetes Care 36:2388-2394. https://doi.org/10.2337/dc12-1971.

Bagheri, M., F. Farzadfar, L. Qi, M. S. Yekaninejad, M. Chamari, O. A. Zeleznik, Z. Kalantar, Z. Ebrahimi, A. Sheidaie, B. Koletzko, O. Uhl, and A. Djazayery. 2018. Obesity-related metabolomic profiles and discrimination of metabolically unhealthy obesity. J. Proteome Res. 17:1452-1462. https://doi.org/10.1021/acs.jproteome $.7 \mathrm{~b} 00802$.

Bala, C., A. E. Craciun, and N. Hancu. 2016. Updating the concept of metabolically healthy obesity. Acta Endocrinol. (Buchar.) 12:197205. https://doi.org/10.4183/aeb.2016.197.

Batch, B. C., S. H. Shah, C. B. Newgard, C. B. Turer, C. Haynes, J. R. Bain, M. Muehlbauer, M. J. Patel, R. D. Stevens, L. J. Appel, L. K. Newby, and L. P. Svetkey. 2013. Branched chain amino acids are novel biomarkers for discrimination of metabolic wellness. Metabolism 62:961-969. https://doi.org/10.1016/j.metabol.2013 .01 .007 .

Beirnaert, C., L. Peeters, P. Meysman, W. Bittremieux, K. Foubert, D. Custers, A. Van der Auwera, M. Cuykx, L. Pieters, A. Covaci, and K. Laukens. 2019. Using expert driven machine learning to enhance dynamic metabolomics data analysis. Metabolites 9:54-67. https://doi.org/10.3390/metabo9030054.

Berry, D. P., K. A. Macdonald, J. W. Penno, and J. R. Roche. 2006. Association between body condition score and live weight in pasture-based Holstein-Friesian dairy cows. J. Dairy Res. 73:487-491. https://doi.org/10.1017/S0022029906002020.

Blüher, M. 2020. Metabolically healthy obesity. Endocr. Rev. 41:405420. https://doi.org/10.1210/endrev/bnaa004.

Chong, J., O. Soufan, C. Li, I. Caraus, S. Z. Li, G. Bourque, D. S. Wishart, and J. G. Xia. 2018. MetaboAnalyst 4.0: Towards more transparent and integrative metabolomics analysis. Nucleic Acids Res. 46(W1):W486-W494. https://doi.org/10.1093/nar/gky310.

Cirulli, E. T., L. Guo, C. Leon Swisher, N. Shah, L. Huang, L. A. Napier, E. F. Kirkness, T. D. Spector, C. T. Caskey, B. Thorens, J. C. Venter, and A. Telenti. 2019. Profound perturbation of the metabolome in obesity is associated with health risk. Cell Metab. 29:488-500. https://doi.org/10.1016/j.cmet.2018.09.022.

Cole, L. K., J. E. Vance, and D. E. Vance. 2012. Phosphatidylcholine biosynthesis and lipoprotein metabolism. Biochim. Biophys. Acta 1821:754-761.

Costello, Z., and H. G. Martin. 2018. A machine learning approach to predict metabolic pathway dynamics from time-series multiomics data. NPJ Syst. Biol. Appl. 4:19. https://doi.org/10.1038/s41540 -018-0054-3.

Crown, S. B., N. Marze, and M. R. Antoniewicz. 2015. Catabolism of branched chain amino acids contributes significantly to synthesis of 
odd-chain and even-chain fatty acids in 3T3-L1 adipocytes. PLoS One 10:e0145850. https://doi.org/10.1371/journal.pone.0145850.

Davis, A. N., J. E. Rico, W. A. Myers, M. J. Coleman, M. E. Clapham, N. J. Haughey, and J. W. McFadden. 2019. Circulating lowdensity lipoprotein ceramide concentrations increase in Holstein dairy cows transitioning from gestation to lactation. J. Dairy Sci. 102:5634-5646. https://doi.org/10.3168/jds.2018-15850.

De Koster, J., M. Salavati, C. Grelet, M. A. Crowe, E. Matthews, R. O'Flaherty, G. Opsomer, L. Foldager, GplusE, and M. Hostens. 2019. Prediction of metabolic clusters in early-lactation dairy cows using models based on milk biomarkers. J. Dairy Sci. 102:26312644. https://doi.org/10.3168/jds.2018-15533.

Doepel, L., H. Lapierre, and J. J. Kennelly. 2002. Peripartum performance and metabolism of dairy cows in response to prepartum energy and protein intake. J. Dairy Sci. 85:2315-2334. https://doi .org/10.3168/jds.S0022-0302(02)74312-9.

Drackley, J. K. 1999. Biology of dairy cows during the transition period: The final frontier? J. Dairy Sci. 82:2259-2273. https://doi .org/10.3168/jds.S0022-0302(99)75474-3.

Edmonson, A. J., I. J. Lean, L. D. Weaver, T. Farver, and G. Webster. 1989. A body condition scoring chart for Holstein dairy cows. J. Dairy Sci. 72:68-78. https://doi.org/10.3168/jds.S0022 -0302(89)79081-0.

Flanagan, J. L., P. A. Simmons, J. Vehige, M. D. Willcox, and Q. Garrett. 2010. Role of carnitine in disease. Nutr. Metab. (Lond.) 7:30. https://doi.org/10.1186/1743-7075-7-30.

Gao, X., W. Zhang, Y. Wang, P. Pedram, F. Cahill, G. Zhai, E. Randell, W. Gulliver, and G. Sun. 2016. Serum metabolic biomarkers distinguish metabolically healthy peripherally obese from unhealthy centrally obese individuals. Nutr. Metab. (Lond.) 13:3343. https://doi.org/10.1186/s12986-016-0095-9.

GfE (German Society of Nutrition Physiology). 2001. Empfehlungen zur Energie- und Nährstoffversorgung der Milchkühe und Aufzuchtrinder [Recommended energy and nutrient supply for dairy cows and heifers]. Ausschuss für Bedarfsnormen der Gesellschaft für Ernährungsphysiologie No. 8. DLG Verlag, Frankfurt am Main, Germany.

Ghaffari, M. H., A. Jahanbekam, H. Sadri, K. Schuh, G. Dusel, C. Prehn, J. Adamski, C. Koch, and H. Sauerwein. 2019. Metabolomics meets machine learning: Longitudinal metabolite profiling in serum of normal versus overconditioned cows and pathway analysis. J. Dairy Sci. 102:11561-11585. https://doi.org/10.3168/ jds.2019-17114.

Ghaffari, M. H., H. Sadri, K. Schuh, G. Dusel, C. Prehn, J. Adamski, C. Koch, and H. Sauerwein. 2020. Alterations of the acylcarnitine profiles in blood serum and in muscle from periparturient cows with normal or elevated body condition. J. Dairy Sci. 103:47774794. https://doi.org/10.3168/jds.2019-17713.

Grummer, R. R., D. G. Mashek, and A. Hayirli. 2004. Dry matter intake and energy balance in the transition period. Vet. Clin. North Am. Food Anim. Pract. 20:447-470. https://doi.org/10.1016/j .cvfa.2004.06.013.

Humer, E., A. Khol-Parisini, B. U. Metzler-Zebeli, L. Gruber, and Q. Zebeli. 2016. Alterations of the lipid metabolome in dairy cows experiencing excessive lipolysis early postpartum. PLoS One 11:e0158633. https://doi.org/10.1371/journal.pone.0158633.

Ingvartsen, K. L. 2006. Feeding- and management-related diseases in the transition cow: Physiological adaptations around calving and strategies to reduce feeding-related diseases. Anim. Feed Sci. Technol. 126:175-213. https://doi.org/10.1016/j.anifeedsci.2005 .08 .003 .

Ingvartsen, K. L., R. J. Dewhurst, and N. C. Friggens. 2003. On the relationship between lactational performance and health: Is it yield or metabolic imbalance that cause production diseases in dairy cattle? A position paper. Livest. Prod. Sci. 83:277-308. https:// doi.org/10.1016/S0301-6226(03)00110-6.

Kaakinen, M., L. Prelot, H. Draisma, M. D. Anasanti, M. R. Jarvelin, and I. Prokopenko. 2018. Machine learning in multi-omics data to assess longitudinal predictors of glycaemic trait levels. Genet. Epidemiol. 42:709. https://doi.org/10.1101/358390.
LeBlanc, S. J., K. D. Lissemore, D. F. Kelton, T. F. Duffield, and K. E. Leslie. 2006. Major advances in disease prevention in dairy cattle. J. Dairy Sci. 89:1267-1279. https://doi.org/10.3168/jds.S0022 -0302(06)72195-6.

Makrecka-Kuka, M., E. Sevostjanovs, K. Vilks, K. Volska, U. Antone, J. Kuka, E. Makarova, O. Pugovics, M. Dambrova, and E. Liepinsh. 2017. Plasma acylcarnitine concentrations reflect the acylcarnitine profile in cardiac tissues. Sci. Rep. 7:17528. https://doi .org/10.1038/s41598-017-17797-x.

McFadden, J. W., and J. E. Rico. 2019. Invited review: Sphingolipid biology in the dairy cow: The emerging role of ceramide. J. Dairy Sci. 102:7619-7639. https://doi.org/10.3168/jds.2018-16095.

Newgard, C. B. 2012. Interplay between lipids and branched-chain amino acids in development of insulin resistance. Cell Metab. 15:606-614. https://doi.org/10.1016/j.cmet.2012.01.024.

Perakakis, N., A. Yazdani, G. E. Karniadakis, and C. Mantzoros. 2018. Omics, big data and machine learning as tools to propel understanding of biological mechanisms and to discover novel diagnostics and therapeutics. Metabolism 87:A1-A9. https://doi.org/10 .1016/j.metabol.2018.08.002.

Puppel, K., and B. Kuczynska. 2016. Metabolic profiles of cow's blood: A review. J. Sci. Food Agric. 96:4321-4328. https://doi.org/10 $.1002 /$ jsfa. 7779 .

Rico, J. E., V. V. Bandaru, J. M. Dorskind, N. J. Haughey, and J. W. McFadden. 2015. Plasma ceramides are elevated in overweight Holstein dairy cows experiencing greater lipolysis and insulin resistance during the transition from late pregnancy to early lactation. J. Dairy Sci. 98:7757-7770. https://doi.org/10.3168/jds.2015 -9519 .

Rico, J. E., Y. Zang, N. J. Haughey, A. G. Rius, and J. W. McFadden. 2018. Short communication: Circulating fatty acylcarnitines are elevated in overweight periparturient dairy cows in association with sphingolipid biomarkers of insulin resistance. J. Dairy Sci. 101:812-819. https://doi.org/10.3168/jds.2017-13171.

Roche, J. R., N. C. Friggens, J. K. Kay, M. W. Fisher, K. J. Stafford, and D. P. Berry. 2009. Invited review: Body condition score and its association with dairy cow productivity, health, and welfare. J. Dairy Sci. 92:5769-5801. https://doi.org/10.3168/jds.2009-2431.

Roche, J. R., K. A. Macdonald, K. E. Schutz, L. R. Matthews, G. A. Verkerk, S. Meier, J. J. Loor, A. R. Rogers, J. McGowan, S. R. Morgan, S. Taukiri, and J. R. Webster. 2013. Calving body condition score affects indicators of health in grazing dairy cows. J. Dairy Sci. 96:5811-5825. https://doi.org/10.3168/jds.2013-6600.

Schicho, R., R. Shaykhutdinov, J. Ngo, A. Nazyrova, C. Schneider, R. Panaccione, G. G. Kaplan, H. J. Vogel, and M. Storr. 2012. Quantitative metabolomic profiling of serum, plasma, and urine by ${ }^{1} \mathrm{H}$ NMR spectroscopy discriminates between patients with inflammatory bowel disease and healthy individuals. J. Proteome Res. 11:3344-3357. https://doi.org/10.1021/pr300139q.

Schuh, K., H. Sadri, S. Häussler, L. A. Webb, C. Urh, M. Wagner, C. Koch, J. Frahm, S. Dänicke, G. Dusel, and H. Sauerwein. 2019. Comparison of performance and metabolism from late pregnancy to early lactation in dairy cows with elevated v. normal body condition at dry-off. Animal 13:1478-1488. https://doi.org/10.1017/ S1751731118003385.

Schulz, K., J. Frahm, U. Meyer, S. Kersten, D. Reiche, J. Rehage, and S. Danicke. 2014. Effects of prepartal body condition score and peripartal energy supply of dairy cows on postpartal lipolysis, energy balance and ketogenesis: an animal model to investigate subclinical ketosis. J. Dairy Res. 81:257-266. https://doi.org/10 .1017/S0022029914000107.

Soriguer, F., C. Gutierrez-Repiso, E. Rubio-Martin, E. Garcia-Fuentes, M. C. Almaraz, N. Colomo, I. Esteva de Antonio, M. S. de Adana, F. J. Chaves, S. Morcillo, S. Valdes, and G. Rojo-Martinez. 2013. Metabolically healthy but obese, a matter of time? Findings from the prospective Pizarra study. J. Clin. Endocrinol. Metab. 98:2318-2325. https://doi.org/10.1210/jc.2012-4253.

Stefan, N., H. U. Haring, F. B. Hu, and M. B. Schulze. 2013. Metabolically healthy obesity: Epidemiology, mechanisms, and clinical 
implications. Lancet Diabetes Endocrinol. 1:152-162. https://doi .org/10.1016/S2213-8587(13)70062-7.

Sundrum, A. 2015. Metabolic disorders in the transition period indicate that the dairy cows' ability to adapt is overstressed. Animals (Basel) 5:978-1020. https://doi.org/10.3390/ani5040395.

Swan, A. L., D. J. Stekel, C. Hodgman, D. Allaway, M. H. Algahtani, A. Mobasheri, and J. Bacardit. 2015. A machine learning heuristic to identify biologically relevant and minimal biomarker panels from omics data. BMC Genomics 16(Suppl. 1):S2. https://doi.org/ 10.1186/1471-2164-16-S1-S2.

van den Berg, R. A., H. C. J. Hoefsloot, J. A. Westerhuis, A. K. Smilde, and M. J. van der Werf. 2006. Centering, scaling, and transformations: Improving the biological information content of metabolomics data. BMC Genomics 7:142-157. https://doi.org/10 .1186/1471-2164-7-142.

Wang, T. J., D. Ngo, N. Psychogios, A. Dejam, M. G. Larson, R. S. Vasan, A. Ghorbani, J. O'Sullivan, S. Cheng, E. P. Rhee, S. Sinha, E. McCabe, C. S. Fox, C. J. O'Donnell, J. E. Ho, J. C. Florez, M. Magnusson, K. A. Pierce, A. L. Souza, Y. Yu, C. Carter, P. E. Light, O. Melander, C. B. Clish, and R. E. Gerszten. 2013. 2-Aminoadipic acid is a biomarker for diabetes risk. J. Clin. Invest. 123:4309-4317. https://doi.org/10.1172/JCI64801.

Wankhade, P. R., A. Manimaran, A. Kumaresan, S. Jeyakumar, K. P. Ramesha, V. Sejian, D. Rajendran, and M. R. Varghese. 2017. Metabolic and immunological changes in transition dairy cows: A review. Vet. World 10:1367-1377. https://doi.org/10.14202/ vetworld.2017.1367-1377.
Wijekoon, E. P., C. Skinner, M. E. Brosnan, and J. T. Brosnan. 2004. Amino acid metabolism in the Zucker diabetic fatty rat: Effects of insulin resistance and of type 2 diabetes. Can. J. Physiol. Pharmacol. 82:506-514. https://doi.org/10.1139/y04-067.

Yang, Y., H. Sadri, C. Prehn, J. Adamski, J. Rehage, S. Dänicke, B. Saremi, and H. Sauerwein. 2019. Acylcarnitine profiles in serum and muscle of dairy cows receiving conjugated linoleic acids or a control fat supplement during early lactation. J. Dairy Sci. 102:754-767. https://doi.org/10.3168/jds.2018-14685.

Yuan, K., R. D. Shaver, S. J. Bertics, M. Espineira, and R. R. Grummer. 2012. Effect of rumen-protected niacin on lipid metabolism, oxidative stress, and performance of transition dairy cows. J. Dairy Sci. 95:2673-2679. https://doi.org/10.3168/jds.2011-5096.

Zeitoun-Ghandour, S., O. I. Leszczyszyn, C. A. Blindauer, F. M. Geier, J. G. Bundy, and S. R. Stürzenbaum. 2011. C. elegans metallothioneins: Response to and defence against ROS toxicity. Mol. Biosyst. 7:2397-2406. https://doi.org/10.1039/c1mb05114h.

Zhou, Z., J. J. Loor, F. Piccioli-Cappelli, F. Librandi, G. E. Lobley, and E. Trevisi. 2016a. Circulating amino acids in blood plasma during the peripartal period in dairy cows with different liver functionality index. J. Dairy Sci. 99:2257-2267. https://doi.org/ $10.3168 /$ jds.2015-9805.

Zhou, Z., M. Vailati-Riboni, D. N. Luchini, and J. J. Loor. 2016b. Methionine and choline supply during the periparturient period alter plasma amino acid and one-carbon metabolism profiles to various extents: Potential role in hepatic metabolism and antioxidant status. Nutrients 9:10-29. https://doi.org/10.3390/nu9010010. 